\title{
Territorio(s) e indigeneidad(es): aportes a partir del trabajo de campo con comunidades comechingonas cordobesas
}

Lucas Palladino

Departamento de Geografía. Facultad de Filosofía y Humanidades. Universidad Nacional de Córdoba, Argentina.

Recibido: 4 de noviembre de 2019. Aceptado: 17 de marzo de 2020.

\begin{abstract}
Resumen
Este artículo pretende aportar al estudio de los procesos de territorialización y comunalización indígena, ofreciendo como material un estudio etnográfico en la provincia de Córdoba, Argentina. En primer lugar, se realiza una descripción de los procesos de re-emergencia indígena y comunalización en contextos de extinción en la provincia de Córdoba. En segundo lugar, se plantea un recorrido analítico sobre las categorías de comunalización, indigeneidad y territorio o procesos de territorialización. En tercer lugar, se muestran dos casos donde, a su vez, operan dos procesos: territorialización y rearticulación de comunidades comechingonas. Aquí se aborda, por un lado, el proceso de comunalización de La Toma en la ciudad de Córdoba capital desde el año 2008, atendiendo al papel que jugó el pasado territorial en la construcción de los sentidos de pertenencia movilizados; por el otro, se analizan los sentidos sobre el pasado y las prácticas de comunalización de la Comunidad Ticas, investigada a partir del 2013, cuando ocupa un terreno ubicado en un espacio rural para realizar sus actividades comunitarias.
\end{abstract}

PALABRAS CLAVE: TERRITORIO. PROCESOS DE COMUNALIZACIÓN. INDIGENEIDAD. REEMERGENCIAS INDÍGENAS. COMECHINGONES.

\section{Territory (ies) and indigeneity (es): contributions from the field work with comechingonas communities of Córdoba}

\begin{abstract}
This article intends to contribute to the study of the processes of territorialization and indigenous communalization by offering an ethnographic study in the province of Córdoba, Argentina. First, a description of the processes of indigenous re-emergency and communalization in contexts of extinction in the province of Córdoba is developed. Second, it proposes an analytical path based on the categories of communalization, indigeneity and territory or territorialization processes. In third place, two cases are shown where, at the same time, two processes of territorialization and rearticulation of comechingones communities operate. From this point the communalization process
\end{abstract}


Territorio(s) e indigeneidad(es): aportes a partir del...

LUCAS PALLADINO

of La Toma in the city of Córdoba capital is addressed, from one side, by following the role that the territorial past played in the construction of the mobilized belongings; on the other side, by analyzing the senses of the past and communalization practices of the Ticas Community, investigated from the 2013, when occupied land located in a rural area developing there its community activities.

KEYWORDS: TERRITORY. COMMUNALIZATION PROCESSES. INDIGENEITY INDIGENOUS REEMERGENCIES. COMECHINGONES.

PALAVRAS-CHAVE: TERRITORIO. PROCESSOS DE COMUNALIZAÇÃO. RESSURGIMENTO INDIGENAS COMECHINGONES.

\section{Introducción}

En el presente trabajo pretendo aportar a la reflexión del análisis de los procesos de territorialización y comunalización indígena, a partir de algunos aportes de mi investigación doctoral. Se trata de una etnografía comparativa llevada a cabo entre los años 2008 al 2017, que involucró trabajo de campo en las comunidades de La Toma (ciudad de Córdoba) y Ticas (en Bialet Massé). ${ }^{1}$ El trabajo examina algunos resultados de investigación y se estructura en tres partes. En primer lugar, describo los procesos de re-emergencias indígenas y comunalización en contextos de extinción en la provincia de Córdoba. En segundo lugar, planteo un recorrido analítico sobre las categorías de comunalización, indigeneidad y territorio o procesos de territorialización, a partir del cual apunto algunas discusiones y ejes de análisis que son retomados en los casos de estudio. En tercer lugar, trabajo con los dos casos. Por un lado, analizo el proceso de comunalización de La Toma en la ciudad de Córdoba capital desde el año 2008, atendiendo al papel que jugó el pasado territorial en la construcción de los sentidos de pertenencia movilizados. Aquí incluyo información obtenida de entrevistas en profundidad, observación participante y talleres de mapeos colaborativos (Ares y Risler, 2013). Por otro lado, analizo los sentidos sobre el pasado y las prácticas de comunalización de la Comunidad Ticas, investigados a partir de mi entrada a campo y de la observación in situ de las actividades, talleres y reuniones colectivas a partir de 2013, cuando la comunidad ocupa un terreno ubicado en un espacio rural realizando allí sus actividades comunitarias. Finalmente, expongo los aportes generales en torno a los ejes de análisis sobre comunalización y territorio en ambas comunidades.

\section{Reemergencias indígenas-comechingonas en la provincia de Córdoba}

En la provincia de Córdoba se expresan procesos de identificación indígena y reconstrucción de comunidades comechingonas desde finales del siglo XX y comienzos del siglo XXI. Se trata de la aparición pública de sujetos que reivindican una identidad originaria asociada a este grupo étnico y, además, buscan reconstruir sus comunidades comechingonas. Hasta entonces, la provincia se consideraba como libre de indios, consecuencia de las prácticas del período colonial y también de la consolidación del Estado argentino (que involucró no sólo la independencia de 1810-1816, sino también la Constitución nacional de 1853, la

1 Se trato de la investigación doctoral en Antropología titulada "Movilizando sentidos de pertenencia comechingones. Una etnografía de los procesos de comunalización y territorialización de las comunidades del Pueblo de La Toma y Ticas (Provincia de Córdoba)" La misma fue dirigida por la Dra. Perla Zusman y el Dr. Diego Escolar. 
Territorio(s) e indigeneidad(es): aportes a partir del...

LUCAS PALLADINO

desarticulación de comunidades y el consecuente avance sobre los territorios indígenas). En esta línea, se consideraba que los pueblos de indios o comunidades indígenas ${ }^{2}$ habían desaparecido desagregados o desatirculados por las políticas liberales del XIX.

Tanto los procesos de identificación indígenas, originarios o aborígenes, como las reemergencias de comunidades también han ocurrido en otras provincias argentinas (Briones, 1998, 2005; Escolar, 2007; Lazzari, 2010, entre otros). En estos contextos los estudios que analizan la formación de grupos indígenas contemporáneos han problematizado el efecto performativo del discurso de blanqueamiento y europeización construido por el Estado nación argentino en la consideración de una identidad nacional homogeneizante (Briones, 1998; Segato, 2007; Bidaseca, 2010). En este marco radican los imaginarios de extinción de grupos indígenas que actúan hoy como disyuntivas y ocasionales sospechas sobre la autenticidad de la identidad indígena de quienes se adscriben como tales. En la provincia de Córdoba, territorio que propició en sus políticas el orgullo del legado colonial y jesuita, se observa la construcción de un poderoso discurso de identidad provincial hegemónica anclado en una procedencia hispánica que fue en detrimento de la otredad indígena y subalterna local. En la medida que estos imaginarios se hicieron presentes, también los grupos indígenas de la provincia fueron ubicados como entidades preterizadas (Bompadre, 2016). ${ }^{3}$

$\mathrm{Al}$ re-visibilizarse las comunidades, ya en el presente siglo, los imaginarios de la extinción, presentes en diversos sectores de la sociedad local, reforzaron las visiones de pureza y de distinción cultural (Pacheco de Oliveira, 2010) propias de las miradas esencialistas u objetivistas sobre la etnicidad. Esto se manifestaba en la consideración de la extinción vía procesos de desagregación de las comunidades comechingonas, efecto del mestizaje biológico o la miscigenación cultural; o bien por las representaciones que colocaban a lo rural como el locus territorial indígena. ${ }^{4}$ Tiempo (pasado), espacio (rural) y cultura (cosificada) se conjugaban para dar lugar a una serie de representaciones sobre la presencia de indígenas en Córdoba. Desde el punto de vista territorial, los imaginarios sobre la presencia de comechingones se expresaron en dos sentidos: en términos de su locación en territorios ubicados en espacios rurales (las sierras, el campo como ámbitos propicios para la sobrevivencia de la comunidad indígena auténtica) o por su asociación limitada al pasado de las encomiendas o pueblos de indios.

En la misma línea que en la escala nacional, la aparición pública de comunidades indígenas comechingonas fue destrabada por un contexto de "juridización del derecho

2 Según Castro Olañeta y Tell (2016) el pueblo de indios era una "unidad social, territorial y jurisdiccional" que en el caso de la Gobernación del Tucumán presentaban tres características distintivas: "un régimen particular de usufructo en común de las tierras asignadas a cada pueblo, cuyo dominio eminente retenía la Corona y se mantenían fuera del mercado; un conjunto de autoridades compuesto por cacique y cabildo indígena; y la obligación de los sujetos de responder a una carga tributaria por su condición de indio originario" (Castro Olañeta y Tell, 2016: 211). Las autoras registran la existencia de más de veinte pueblos de indios en la provincia de Córdoba, algunos de los cuales fueron reducidos tempranamente en la sociedad colonial de los siglos XVI y XVIII y otros categorizados como comunidades indígenas (categoría que utiliza el gobierno provincial de Córdoba en el siglo XIX), cuyas tierras fueron expropiadas y subdivididas entre 1880 y 1900 (Cosquín, Quilino, San Marcos, Soto, Pichana y La Toma).

3 Se reconoce la presencia de grupos comechingones, sanavirones y ranqueles como los pueblos originarios.

4 Para Stagnaro "las representaciones construidas desde el imaginario social hegemónico niegan la contemporaneidad de los indígenas, o bien consideran su presencia como una anomalía; es decir, ubican a lo originario en un antes y en un afuera que invisibiliza, o mejor aún, visibiliza a medias, ya que relativiza las presencias contemporáneas y coterráneas en un contexto de emergencias e identificaciones comechingón, poniéndolas en cuestión y discusión" (2014:1). 
Territorio(s) e indigeneidad(es): aportes a partir del...

LUCAS PALLADINO

indígena" (Briones, 2005) ${ }^{5}$ En Córdoba no existía información oficial respecto de la presencia de indígenas hasta la publicación de los datos de la Encuesta Complementaria de Pueblos Indígenas (ECPI) realizada entre los años 2004 y 2005 por el Instituto Nacional de Estadísticas y Censos (INDEC). En términos generales, los resultados del censo muestran que 5.119 personas se consideraron vinculadas al "pueblo comechingón" en la Provincia de Córdoba. ${ }^{6}$ Ahora bien, dicha visibilización política institucional aún no se reflejaba en los mapas de pueblos originarios elaborados por las instituciones oficiales. De hecho, la cartografía de difusión sobre la distribución de grupos originarios en Argentina todavía ubicaba un vacío en Córdoba.

Mi interpretación de la coyuntura política y social en el que participan las y los adscriptos indígenas y las respectivas comunidades permite comprender dos momentos diferentes: el primero, de institucionalización o rearticulaciones comunales y procesos de reconocimiento estatal del INAI (período comprendido principalmente entre los años 2008-2011); el segundo, de las denuncias, reclamos y reivindicaciones de derechos de las comunidades ya reconocidas legal o legítimamente como tales. Para la primera coyuntura, el tema central en diferentes agendas indígenas pasaba tanto por establecer y rearticular a la comunidad al interior (fortaleciendo la membresía) como al exterior (construyendo un relato de legitimación de la identidad comechingona en un contexto de extinción y, en efecto, visibilizando a las comunidades). En la segunda etapa, en cambio, una vez reconocidas por el Estado nacional, las reivindicaciones oscilaron sus reclamos entre su constitución como comunidades ante el Estado provincial y sus derechos territoriales, arqueológicos y óseos. En este marco, el Estado provincial dictó las leyes de reconocimiento de las comunidades indígenas de Córdoba (2015).

La primera etapa se caracterizó por un proceso intenso de institucionalización o reorganización de las comunidades (Bompadre, 2016), correspondiéndose con el accionar de la mayor parte de grupos comechingones de la provincia de Córdoba que comienzan los trámites de inscripción en el Registro Nacional de Comunidades Indígenas (RENACI) para obtener personería jurídica, empezando a otorgarse estos entre finales del año 2009 e inicios del 2010. Si hasta el 2010 el número de comunidades indígenas en Córdoba no era mayor a seis, ya para el 2018 se habían rearticulado o manifestaron su existencia más de veinte comunidades.

Más tarde, en una segunda etapa, aparecieron reivindicaciones de algunos grupos ya constituidos como comunidades y además reconocidos por el INAI -teniendo en cuenta que no todas decidieron solicitar personería jurídica-. Es en esta instancia que las comunidades organizan eventos, celebraciones, programas, establecen convenios con los Estados municipales o diferentes instituciones (universidades, ONG, organizaciones) y reclaman o demandan derechos sobre el territorio, el patrimonio arqueológico y los restos óseos. Además, se observan denuncias sobre invasión de tierras, desmontes,

5 Este proceso de visibilización y juridización fue tanto producto del activísimo indígena como de la aplicación de tratados y convenios internacionales. A partir de 1990 se observa un proceso de reconocimiento de comunidades apoyado en un contexto político-institucional que se expresa en la reforma constitucional (1994) y en la creación de agencias gubernamentales como el Instituto Nacional de Asuntos Indígenas (INAI) (creado en 1985 por efecto de la Ley $\mathrm{N}^{\circ} 23302$, pero reglamentado desde 1990). Ello facilitó la tramitación de las personerías jurídicas a nivel nacional y derivó en el crecimiento de reivindicaciones en provincias en que se consideraba que los indígenas estaban extintos.

6 Los resultados del ECPI 2004-2005 se pueden consultar en: http://estadistica.cba.gov.ar/Encuestas/ PueblosInd\%C3\%ADgenas/PuebloComeching\%C3\%B3n/tabid/443/language/es-AR/Default.aspx 
Territorio(s) e indigeneidad(es): aportes a partir del...

LUCAS PALLADINO

saqueo de piezas arqueológicas o avasallamiento de sitios sagrados, pero también reclamos sobre restituciones tanto de restos arqueológicos como de territorios. Cabe destacar que, aunque las comunidades no hubieran sido reconocidas oficialmente por las leyes provinciales, algunas oficinas dependientes de agencias gubernamentales provinciales ya trabajaban con comunidades indígenas comechingonas. Al mismo tiempo, algunos municipios ya reconocían a los pueblos originarios de manera directa, tanto en actas y ordenanzas municipales como en la inauguración de predios o espacios públicos. Finalmente, es preciso remarcar que, así como apareció un apogeo de comunidades, también hubo fracturas, desarticulación o reorganización de otras.

Por su parte, esta creciente movilización indígena en Córdoba puja también por el reconocimiento de derechos en la esfera del Estado provincial. Así, recién en el año 2015 se sancionaron las primeras leyes provinciales que involucraban derechos de pueblos indígenas. Por un lado, la Ley $\mathrm{N}^{\circ} 10.316$ de Creación del Registro de Comunidades de Pueblos Indígenas de la Provincia de Córdoba y, por el otro, la Ley Nº 10.137 de Adhesión a la Ley Nacional $\mathrm{N}^{\circ} 25.517$ (de Restitución de Cuerpos Humanos a Pueblos Originarios).

\section{Desestabilizando geografías oficiales de territorialización indígena}

Ahora bien, esta proliferación de comunidades en el territorio provincial, intensificada en la segunda etapa, no implicó que se eliminaran ni silenciaran los relatos y discusiones sobre la autenticidad indígena (Handler, 1986; Escolar, 2007), ni tampoco que los sentidos de pertenencia movilizados en la comunalización se hayan congelado al momento de su institucionalización. De hecho, a partir de las prácticas políticas gubernamentales se reconfigurarán viejos enunciados sobre la legitimidad de los reclamos indígenas. Además de las discusiones diacríticas en torno a los marcadores biológicos y culturales legítimos de lo comechingón (utilizados como indicadores de autenticidad indígena), un punto sobre el cual giraron algunas discusiones fue el de las marcaciones del origen territorial y la formación de comunidades en espacios y localidades pertenecientes a encomiendas coloniales o pueblos de indios y comunidades indígenas del territorio provincial.

Anteriormente mencioné que en algunos sectores de Argentina los grupos indígenas son imaginarizados como habitando espacios rurales (Escolar, 2007; Szulc, 2004). Sin embargo, como ha sostenido Gordillo (2010), en algunos casos las representaciones hegemónicas conectan a las comunidades con sitios fijos de ocupación histórica y con geografías estables; a pesar de que las mismas comunidades indígenas recalquen las trayectorias históricas de movilidad como aspecto característico de su territorialización histórica. Cabe aclarar que parte del imaginario acerca de la localización de los comechingones en la provincia de Córdoba encuentra sus fuentes en la obra Los Comechingones, de Antonio Serrano (1945). A partir de esta obra se popularizó la división de grupos étnicos comechingones y sanavirones en la provincia, donde los primeros aparecen localizados en el margen oeste y norte de las Sierras Centrales comprendidas en Córdoba y norte de San Luis. ${ }^{7}$

7 Serrano, arqueólogo y director del Instituto de Arqueología, Lingüística y Folklore, fue un pionero al escribir Los Comechingones, texto publicado en 1945. Se trata de la primera obra donde se buscan describir los elementos que distinguían a la cultura local entre ellos las características fenotípicas, culturales, geohistóricas, lingüísticas, entre otras. Esta obra figura por primera vez la división de los grupos étnicos de la provincia de Córdoba entre Comechingones (al oeste), Sanavirones (al nordeste) y Ranqueles (al sur). El autor realiza la primera "carta étnica" donde atribuye la localización de los primeros "propiamente la provincia de los comechingones comprendía las sierras a uno y a otro lado" (Serrano, 1945:19). 
LUCAS PALLADINO

En el caso de las comunidades comechingonas cordobesas contemporáneas, se observa una diversidad de trayectorias que marcan diferentes experiencias y procesos de identificación con territorios en espacios rurales y urbanos, con sitios asociados a la existencia de encomiendas, pueblos de indios, reducciones coloniales y comunidades indígenas del siglo XIX. Muchas veces, se adscribe a estos ámbitos geográficos a partir de establecer lazos genealógicos y reconocer narrativamente una continuidad espacial con comuneros, curacas, caciques o naguanes presentes, sobre todo, en las figuras de los pueblos de indios y comunidades indígenas. Otros han manifestado su identificación territorial sobre la base de diásporas pasadas, adscribiendo hoy como su territorio a varios sitios y lugares de la provincia, reivindicando su origen principalmente en las zonas del centro, oeste y norte de la provincia de Córdoba.

A modo ilustrativo se ha realizado la siguiente cartografía para mostrar la presencia de comunidades comechingonas re-comunalizadas hacia el 2017 y la localización de pueblos de indios y comunidades indígenas en la provincia de Córdoba reconocidas en el trabajo de Castro Olañeta y Tell (2016).

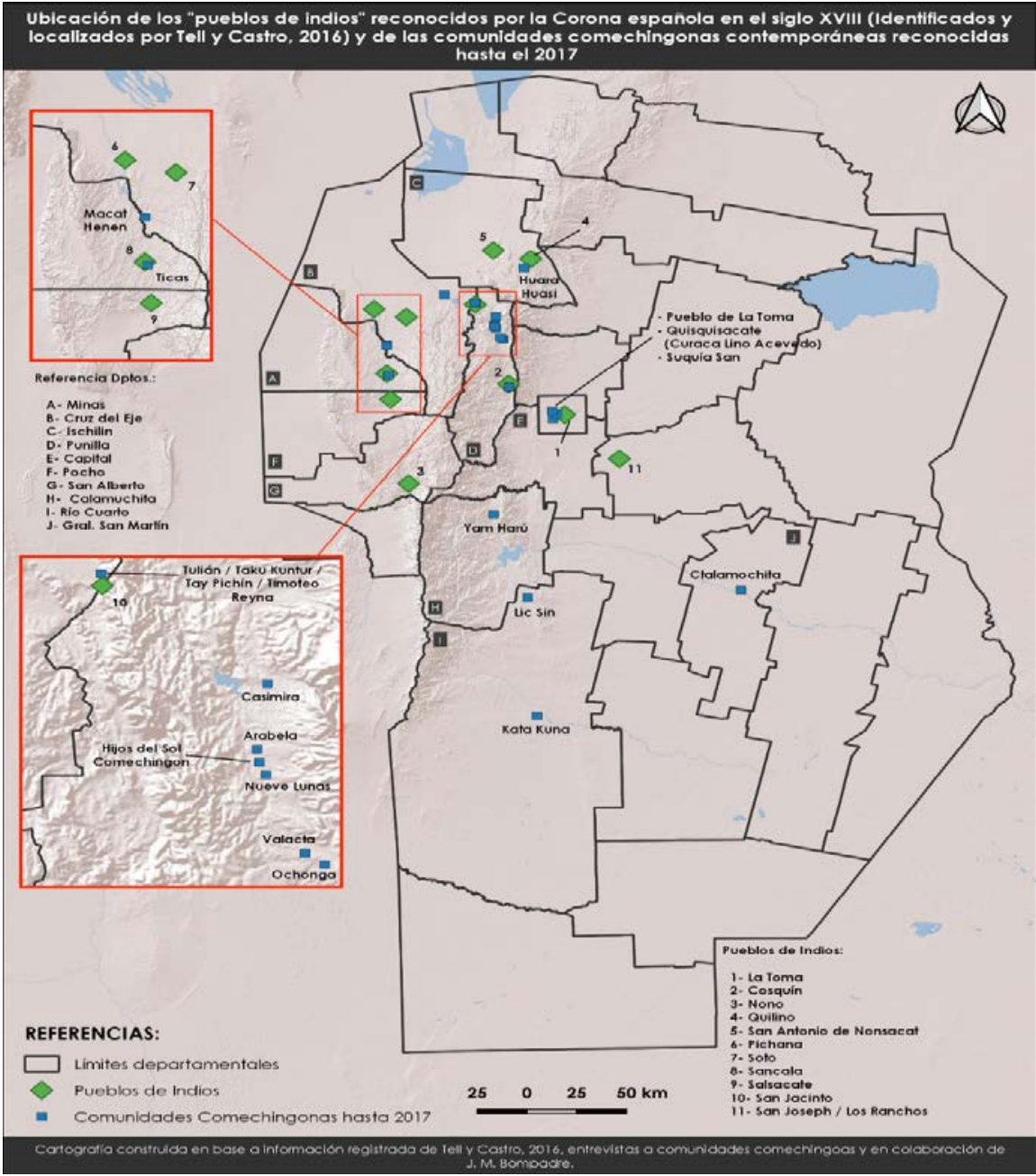

Figura 1. Fuente: cartografía realizada por Oscar Vives en Palladino, 2020. 
LUCAS PALLADINO

Finalmente, es destacable que, más allá de las discusiones sobre el imaginario territorial de los procesos de reemergencia de grupos comechingones y frente los primeros relatos que sembraron sospechas sobre si estas reemergencias correspondían con intereses por la obtención de tierras, muchas comunidades no activaron reivindicaciones que tuvieran al territorio como finalidad primera. A pesar de ello, puede observarse que el territorio juega un rol clave en la construcción identitaria de los adscriptos comechingones en diferentes comunidades y que las memorias territoriales también aportan herramientas en el proceso de comunalización, movilización política y territorial de las mismas comunidades.

A partir de ello, en este trabajo pretendo explorar el papel que juega el territorio en dos procesos significativos de comunalización de la provincia, por estar ubicados en dos ámbitos geográficos diferentes. Por un lado, en la rearticulación comunal de La Toma, localizada en el espacio urbano de la ciudad de Córdoba y que se reivindica como perteneciente al antiguo Pueblo de Indios de La Toma (reducción indígena del oeste de la ciudad, luego expropiado y desarticulado por el gobierno provincial del siglo XIX). Por el otro, la Comunidad Ticas, ubicada en un espacio rural de Bialet Massé que denominan Cochatalasacate (departamento de Punilla), pero que además reivindica su origen territorial en la región de San Carlos Minas (departamento homónimo) en la región de Traslasierra.

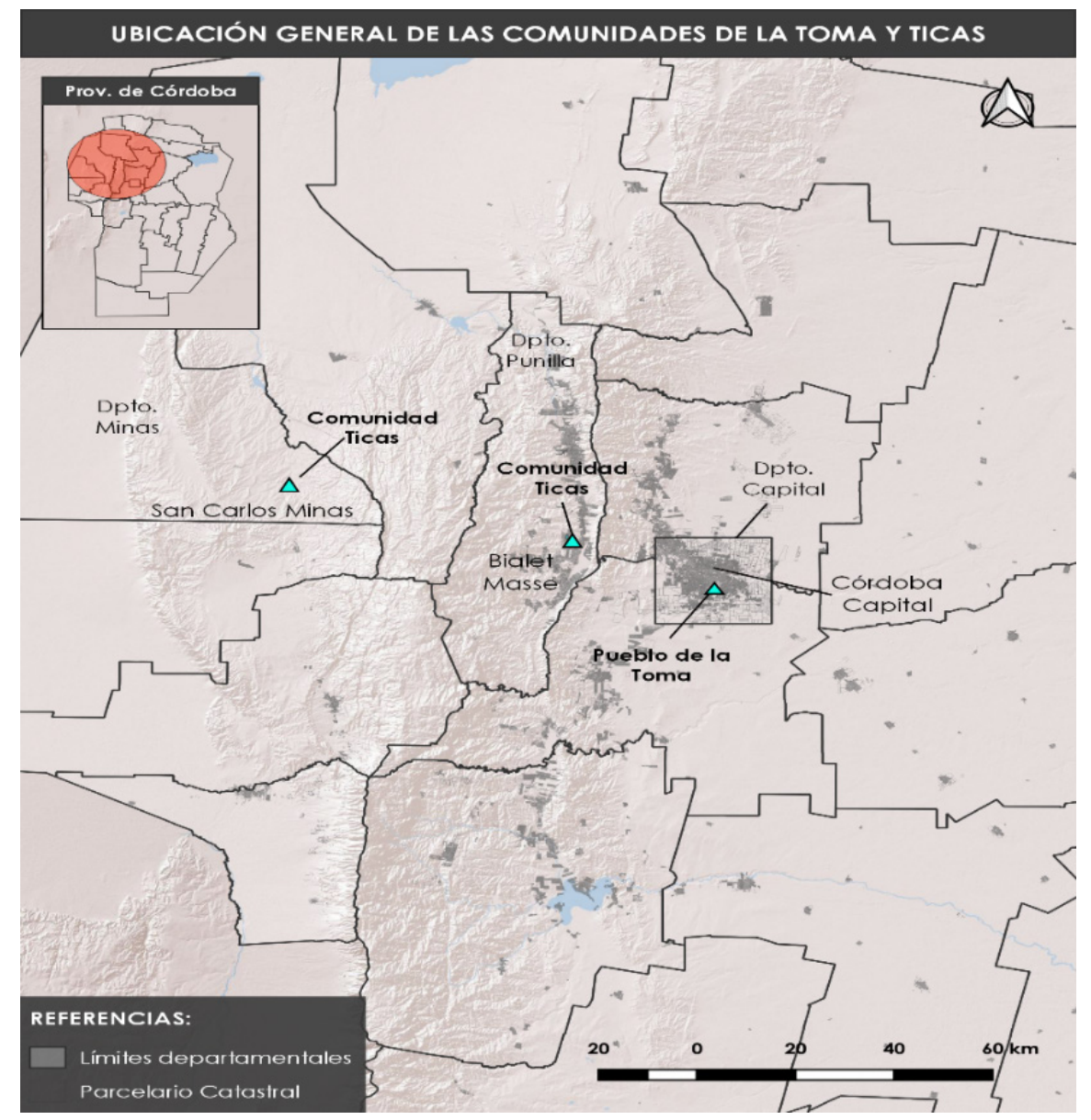

Figura 2. Fuente: cartografía realizada por Oscar Vives. Palladino, 2020. 


\section{Abordar las reemergencias indígenas: el territorio, la indigeneidad y los procesos de comunalización indígena}

Muchos estudios que trabajan con procesos de re-emergencias indígena se separan de la concepción que entiende a la identidad como una condición ontológica, estática y cerrada. La aboriginalidad o indigeneidad, tal como lo sostienen Briones (1998) o Pratt (2010), puede pensarse como un proceso de identificación identitaria que es relacional, donde son activados y movilizados sentidos sobre el "ser indígena" en las complejas dinámicas y tramas que involucran relaciones y marcaciones de otros. Así, Briones (1998) sostiene que aboriginalidad es un proceso de marcación étnica en el que está implicada la producción cultural de lo aborigen como forma particular de alteridad. Más que el producto o la sustancia interesa analizar los procesos de auto y hetero-marcación, los elementos que están en juego y que constituyen, en todo caso, la apelación a lo que Pratt (2010) llama las "fuerzas potenciales", como el sentido compartido de una lengua, el pasado en común, las memorias históricas de opresión, el parentesco y el territorio.

Otro elemento de análisis para tener en cuenta es el concepto de procesos de comunalización de James Brow (1990). Estudios sobre formación de grupos indígenas se han valido de dicho término para dar cuenta de los sentidos de pertenencia movilizados por los adscriptos en la dinámica de formación de colectivos (Bompadre, 2016; Briones y Ramos, 2016; Cañuqeo y Pérez, 2015; Escolar, 2007; Palladino, 2010, 2020; Saldi, 2012). Por un lado, estos trabajos tensionan el concepto de comunidad que ofrecen las definiciones tradicionales, basadas en las ideas de contigüidad territorial o co-presencia (Barros, 2000; Gupta y Ferguson, 2008), conceptualizando un "estar juntos" que no necesariamente está en armonía con las definiciones que marca la estatalidad (Briones y Ramos, 2016; Cowan Ross y Nussbaumer, 2013). Por el otro, el concepto de comunalización en el marco de grupos indígenas en procesos de reorganización y reconstrucción de sus identidades grupales permite analizar las tensiones y diálogos con las categorías estatales de reconocimiento implicadas en la tramitación de la personería jurídica.

Brow (1990) considera que las comunidades no pueden ser caracterizadas a partir de la simple suma de miembros agrupados en el espacio, sino por los sentimientos de pertenencia movilizados para generar el sentido de una identidad compartida. Estos suponen un sentido de unión y de solidaridad entre quienes adscriben su membresía. De esta manera, la comunidad se constituye en ese proceso dado por los patrones de acción que promueven dichos sentimientos de pertenencia. El autor destaca que hay ciertos elementos que son útiles para otorgar cohesión al grupo. Así, los sentimientos de pertenencia son promovidos a partir del sentido de la primordialización, por un lado, y por las prácticas de reinvención de la tradición autorizada, por el otro.

La primordialización implica que las relaciones sociales son consideradas como naturales y que poseen un origen común, experimentadas como si poseyeran una inevitabilidad original y natural, considerada su existencia desde tiempos inmemorables (Brow, 1990:2). Por el otro lado, el concepto de tradición es entendida como "conjunto de prácticas, regidas normalmente por reglas manifiestas o aceptadas tácitamente y de naturaleza ritual o simbólica, que buscan inculcar ciertos valores y normas de comportamiento por medio de la repetición, lo que implica de manera automática una continuidad con el pasado" (Hobsbawm y Ranger, 2002:1). 
Territorio(s) e indigeneidad(es): aportes a partir del...

LUCAS PALLADINO

De esta manera, el aporte analítico de Brow es útil para comprender los sentidos movilizados por los grupos indígenas en sus procesos de reconstrucción que apelan a reforzar el pasado, la genealogía y los elementos territoriales en sus prácticas del presente. Cabe aclarar que el concepto emerge en el análisis de los procesos de construcción de Estados nacionales modernos. De aquí que dicha noción se utilizó para ver qué sentidos operan en los procesos de formación de grupos indígenas considerados extintos. Así, diversos estudios se plantearon ver cómo juegan los procesos de primordialización de los vínculos y el pasado en los grupos recientemente rearticulados.

Ahora bien, los estudios de comunalización de grupos indígenas en Argentina han podido deconstruir la idea de comunidad, mostrando cómo los vínculos son cultural y socialmente recreados en las dinámicas de la primordialización y en las mismas prácticas performativas de la tradición, pero menos se ha investigado sobre cómo el territorio participa como elemento clave en estos procesos de cohesión comunitaria.

\section{Revisando el concepto de territorio para ampliar la perspectiva de comunalización}

Establecer un punto de partida para pensar la relación entre procesos de territorialización, comunalización e indigeneidad implica revisar el mismo concepto de territorio, cuestión que sobrepasa los objetivos de este artículo. Sin embargo, es preciso aclarar el distanciamiento de aquella visión predominante presente en la geografía política de finales de siglo XIX y comienzos del XX, en la que el territorio era visto como un ámbito jurisdiccional o como un área de dominación estatal. Recuperaré la perspectiva relacional e integradora (Haesbaert, 2004) para dar cuenta de la presencia de múltiples actores, relaciones, escalas, procesos, que definen y construyen los territorios. Así, se entiende que el territorio es construido mediando estos procesos y que el análisis debe contemplar las relaciones sociales, de poder e históricas.

Rogerio Haesbaert (2004) ha revisado los conceptos de desterritorialización y re-territorialización a través de distintas disciplinas. Su propuesta critica una serie de estudios (Badie, 1995; Appadurai, 1996; Virilio, 1997) que sostuvieron la proliferación de procesos de desterritorialización a escala global. ${ }^{8} \mathrm{El}$ autor considera que estas perspectivas suponen que el territorio es definido por sus aspectos materiales, en tanto cualquier movimiento o desplazamiento implicaría una pérdida de control de los grupos (especialmente del Estado) sobre el espacio. Por su parte, en el plano simbólico la movilidad espacial, puso en cuestión la correspondencia entre nación y homogeneidad cultural.

Así, y en una lectura posestructuralista, propone pensar a los procesos de desterritorialización como simultáneos a los de re-territorialización y concomitantes a la producción de sentidos, identificación y reapropiación simbólica de diferentes agentes sociales en el

8 Este cuerpo de trabajos consideraba que la comprensión espacio-tiempo (Harvey, 1994), propia del capitalismo flexible, había provocado procesos de desmaterialización, la pérdida del control y de los vínculos de las sociedades con su espacio estatal-nacional. A su vez, suponían que aspectos tales como la "globalización", el "debilitamiento de fronteras" y la "homogeneización cultural" habrían generado desarraigo y des/identificación en diferentes grupos sociales de los Estados. 
Territorio(s) e indigeneidad(es): aportes a partir del...

LUCAS PALLADINO

espacio. ${ }^{9}$ Entendiendo que el territorio se construye y envuelve una dimensión simbólica y cultural, "y una dimensión concreta, de carácter político-disciplinar" (Haesbaert, 2007:94), su perspectiva permite abordar otros procesos de territorialización, como la constitución de territorios múltiples, fragmentarios, no contiguos, flexibles y dinámicos (cargados de múltiples velocidades y temporalidades). Así, ya no interesa solamente el control político del espacio, la delimitación areal o zonal, sino que se pone el énfasis en el estudio de los procesos y relaciones, especialmente el diálogo entre dimensiones materiales y simbólicas vinculadas a la producción y control espacial de los agentes sociales en el espacio.

\section{La perspectiva relacional e integradora en el análisis de procesos de comunalización indígena}

Esta dimensión relacional e integradora del territorio permite complementar reflexivamente las perspectivas teórico-epistemológicas que están presentes en algunos estudios que vienen trabajando sobre experiencias vinculadas a movilizaciones indígenas y territorio (nuestros antecedentes). En este sentido, cabe mostrar un breve panorama de estudios que abordan el concepto de territorio en el estudio de grupos indígenas en América Latina dentro los campos de la antropología social y las denominadas geografías indígenas (Berrios, Sepúlveda y Palomino-Schalscha, 2015).

En primer lugar, se identifica la perspectiva de la antropología política representada por la visión de Pacheco de Oliveira (2010). El autor utiliza la noción de "modos de territorialización" para dar cuenta de diferentes maneras de "reorganización social" que implican la creación de una nueva unidad sociocultural mediante el establecimiento de una identidad étnica diferenciadora, la constitución de mecanismos políticos especializados, la redefinición del control social sobre los recursos naturales y la reelaboración de la cultura y la relación con el pasado (Pacheco de Oliveira, 2010:19). Esta noción aparece más ligada a la tradición "política" del concepto de territorio. Interesa, entonces, en cuanto permite caracterizar los modos de organización político-administrativos y, a su vez, atender la tensión entre los modos de organización política, especialmente frente a la imposición de la reorganización territorial de la que fueron objeto los grupos indígenas tras las coyunturas coloniales y republicanas. De hecho, esta definición es interesante a la hora de analizar los procesos de comunalización contemporáneos, precisamente para dar cuenta de las reivindicaciones actuales en el marco de la articulación con los procesos históricos de larga duración. Ahora bien, la propuesta de Oliveira puede vincularse con otros enfoques que atiendan a la multidimensionalidad de la experiencia territorial en los procesos de identificación.

En segundo lugar, existe otro cuerpo de trabajos que, en América Latina, abordan tanto las cuestiones de soberanía indígena y autodeterminación como temas sobre conflictos y luchas por los recursos naturales o la tierra. En términos generales, estos estudios oponen las representaciones de las comunidades indígenas a las de los grupos de poder, empresas o Estados. A partir de este punto de vista, los estudios se centran en

9 Haesbaert toma la perspectiva de Deleuze y Guattari (1994), quienes entendieron a la desterritorialización como proceso un permanente en devenir, dando lugar a pensar en el movimiento, en el encuentro y en las conexiones. Desde el punto de vista de estos autores, todo movimiento de desterritorialización se acompaña de otro concomitante de re-territorialización. Ellos proponen una la ontología trazada por el devenir de la teoría de las multiplicidades del modelo del rizoma (Haesbaert, 2004:114). 
Territorio(s) e indigeneidad(es): aportes a partir del...

los conflictos por tierras y territorios que emergen entre grupos indígenas, campesinos y empresas o agencias estatales (Porto Gonçalves, 2004; Mançano Fernández, 2009, entre otros). Cabe aclarar que, si bien los análisis pueden contemplar lo indígena, no todos estos estudios tematizan necesariamente las re-emergencias indígenas o tratan los procesos de comunalización contemporáneos. Por otro lado, en estos trabajos se observa cierto interés en los conflictos interétnicos, aunque, sin embargo, se observa una problematización menor de los aspectos simbólicos y al interior de un grupo en cuestión.

En tercer lugar, existe también un corpus en emergencia de estudios que parten de conceptualizaciones y prácticas nativas sobre/en el territorio para pensar las tensiones modernas naturaleza/cultura a partir del giro ontológico (Escobar, 2014; Nates Cruz, 2011; Palomino-Schalscha, 2015). Se trata de una línea menos explorada en Argentina, pero que ofrece aportes teóricos para pensar los conflictos ontológicos que implican los puntos de vista y las agencias gubernamentales. La línea que rescato trata de la relación entre lo simbólico (los sentidos indígenas movilizados en las prácticas político-territoriales) y las mismas prácticas de dominación y control espacial (donde se encuentra la tensión con las agencias implicadas en los mundos modernos). Se trata de enfoques más novedosos e interesantes epistemológicamente que, sin embargo, exploran menos lo discursivo y las relaciones de poder en la construcción de prácticas de identificación y estrategias de movilización política. ${ }^{10}$

Una de las discusiones que ofrecen los trabajos que abordan la relación territorio e indigeneidad tiene que ver con la cuestión de la construcción de territorios contiguos, demarcados y fijos. Así, un tema relevante es el de la soberanía territorial (Brown, 2010; Clifford, 2010). Desde esta perspectiva, mientras algunos estudios realizan una crítica a la producción espacial del Estado nación, cuya expansión territorial implicó el desplazamiento de grupos indígenas; otros discuten la cuestión de autodeterminación territorial indígena. Los trabajos de Starn (2010) y Brown (2010) muestran cómo en sus procesos de movilización política existen grupos indígenas que construyen proyectos de autodeterminación territorial. Mientras en algunos casos estos proyectos contemplan procesos de estabilización territorial semejantes a la manera en la que lo hacen los Estados nacionales, en otros casos implican tensiones con estos.

Ahora bien, este énfasis en la cuestión de la soberanía y la autodeterminación, como componentes inherentes a la perspectiva territorial de grupos indígenas, corre el riesgo de no admitir la indigeneidad con nociones como estabilidad o fijación etnoespacial. De esta manera, surge el interrogante: ¿̇qué lugar existen para los procesos de territorialización indígena que se han caracterizado por la movilidad espacial más que por su sedentarismo? Podríamos pensar en retomar elementos analíticos para examinar prácticas territoriales de indígenas que no residen en sus territorios "históricos" o que conciben que su territorio puede construirse material o simbólicamente en la movilidad,

10 He identificado cuatro líneas de trabajos sobre territorio, indigeneidad y comunalización en Argentina, La primera ofrece una visión administrativa y jurídica de la reorganización territorial de los grupos indígenas, fundamentada en los aportes de Foucault sobre gubernamentabilidad y disciplinamiento (Katzer, 2011; Saldi, 2012). La segunda, toma en cuenta las prácticas territorialización de las comunidades a partir de sus memorias y experiencias históricas en el marco de la "desincorporación estatal de los grupos indígenas en la Patagonia" (Del Río y Ramos, 2011). La tercera pone en juego las disputas entre las concepciones del territorio que ofrecen las comunidades indígenas y aquellas estatales implicadas en el proceso de relevamiento territorial del INAI (Ley N²6.160) (Arias, 2010; Cañuqueo, 2015). La cuarta perspectiva hace eco del giro ontológico y sus implicancias territoriales en el estudio de las de comunidades indígenas del Noroeste (Cladera, 2013), Noreste (Salamanca, 2012) y Patagonia (Ramos, 2016;). Para una profundización ver Palladino, 2020. 
Territorio(s) e indigeneidad(es): aportes a partir del...

LUCAS PALLADINO

como por ejemplo a partir de la experiencia de la diáspora y el exilio, experiencias que vincularían la identificación con varios sitios y al "multiapego" (Clifford, 2010).

Un antecedente relevante a esta discusión es el trabajo de Gastón Gordillo (2010) que, en su análisis sobre los procesos de re-territorialización guaraní en Salta y Jujuy, muestra como los conflictos territoriales generan disputas identitarias en las que priman representaciones diferenciales de la indigeneidad ligadas a diferentes visiones de la territorialidad. Así, el desplazamiento contemporáneo de grupos guaraníes hacia ámbitos no ocupados por ellos previamente abrió una disputa territorial que sacó a la luz los imaginarios regionales sobre la relación entre identidad y territorio indígena. Gordillo menciona que esta búsqueda de re-territorialización guaraní tensiona las argumentaciones de una "espacialidad estable" anclada en "metafísicas sedentarias" (Malkki, 1997 en Gordillo, 2010:209) que subyace en las lecturas hegemónicas en los grupos de poder locales, y permiten pensar tanto en maneras cambiantes y dinámicas de territorialización como en construcción de narrativas sobre la identidad territorial indígena, presentes tanto entre los noindígenas como en los propios adscriptos.

Este tipo de discusiones pueden ser sintetizadas con la idea de "fijación etno-espacial", tal como lo usan De la Cadena y Starn (2010) para problematizar los imaginarios que consideran que los grupos indígenas viven en tierras histórica y tradicionalmente ocupadas por sucesivas generaciones. Además, de no admitir la movilidad y de considerar una identificación étnica-indígena asociada o legitimada por un territorio fijo, también existe el riesgo analítico de: "resaltar los vínculos nativos a un territorio fijo, puede además reforzar de manera involuntaria una visión predominante (...) de los aborígenes como 'no domesticados' y 'salvajes' -y una visión análoga de quienes viven en ciudades como nativos 'no auténticos' y 'no reales”' (Merlan, 2010 en De la Cadena y Starn, 2010:24). Esto provocaría un énfasis en la construcción de estereotipos de lo indígena como localizados en ámbitos rurales, cuestión que refuerza los debates de autenticidad étnica vívidas en los propios espacios urbanos donde se llevan a cabo procesos de identificación indígena y comunalización.

Pero, también, estos aportes buscan pensar los procesos de identificación indígena más allá de la fijación, la estabilidad o a la presencia histórica en un ámbito geográfico determinado. Así incorporan la cuestión de los flujos y la movilidad. En este sentido, se busca tomar en cuenta las vivencias de construcción de territorialidad no solo a través de prácticas de autonomía, autodeterminación o cierre espacial, sino también trabajar las experiencias de desarraigo y desplazamiento que caracterizan a varios grupos indígenas o, más aún, la experimentación de la multiterritorialidad en el devenir indígena y devenir comunidad en la yuxtaposición de espacios rurales y urbanos. Entonces, estas perspectivas citadas permiten matizar el enfoque de la construcción territorial desde los ámbitos estáticos y cerrados a otros que contemplen múltiples áreas o donde la dimensión material del territorio no es la única definidora de la indigeneidad.

Este recorrido problemático es importante para el análisis de procesos de territorialización implicados en las experiencias de identificación indígena-comechingón y comunalización. ¿Hasta qué punto estas nociones de fijación y rigidez sirven a los fines de comprender las dinámicas espaciales e identitarias implicadas en los procesos 
LUCAS PALLADINO

de reemergencias y comunalización comechingones contemporáneos? Esta inquietud permite cuestionar críticamente los imaginarios y perspectivas histórico-políticas atadas a los contextos coloniales y republicanos que han considerado una reducción o desaparición de comarcas indígenas, encomiendas, pueblos de indios y también comunidades indígenas como uno de los aspectos que, desde la dimensión del territorio, habrían conducido a la desaparición o extinción de los propios indígenas de Córdoba. También permite entender a dichas reducciones como los espacios legitimados para la supervivencia de las comunidades o adscriptos indígenas en el pasado. ¿Qué otros modos habilitados de territorialidad se narran en las pertenencias indígenas comechingonas en las prácticas de comunalización contemporáneas?, ¿de qué manera se expresan esos procesos de comunalización y territorialización comechingona en contextos de reemergencias?, ¿existen tensiones entre estas narrativas, prácticas y procesos de territorialización indígena con aquellas perspectivas y sentidos hegemónicos?

En este marco, y teniendo en cuenta la existencia de los aspectos mencionados como contexto clave, emerge en esta investigación el interés por explorar de qué manera participan los sentidos de pertenencia sobre el territorio en los procesos de comunalización y cómo se relacionan con los mismos sentidos que construye performativamente la comunidad.

\section{La (re)construcción contemporánea de las comunidades comechingonas del Pueblo de La Toma (ciudad de Córdoba) y Ticas (Bialet Massé)}

\section{El Pueblo de La Toma: ancestralización del territorio y construcción de pasado comunal}

La Comunidad Comechingón del Pueblo de La Toma se reorganizó a finales del 2007 y comienzo del 2008, cuando se visibilizó públicamente como originaria. Esta comunidad ha tenido la particularidad de ser la primera que se reivindica de forma yuxtapuesta a un espacio urbano, identificándose como indígenas preexistentes a la fundación de la ciudad de Córdoba (1573).

Se trata de un área geográfica habitada por diferentes grupos o comarcas indígenas y que, desde la perspectiva de los adscriptos, fue reducida al margen oeste de la ciudad, donde se construyó una acequia y una toma (que le diera el nombre al pueblito allí ubicado) para abastecer de agua a la Córdoba colonial (siglos XVI a XIX). El Pueblo de La Toma fue sometido a un proceso de expropiación de tierras durante las últimas décadas del siglo XIX hasta 1910 cuando pasa a denominarse barrio Alberdi. ${ }^{11}$

11 Pueblo Alberdi fue el nombre que sucedió a La Toma, una vez ingresada como barrio a la ciudad de Córdoba, tras la sanción de una ordenanza municipal que en 1910 hizo homenaje a Juan Bautista Alberdi con motivo del centenario de la independencia nacional. Se trató de la creación de uno de los principales "BarrioPueblo" de Córdoba y cuya extensión era mayor que el actual barrio Alberdi, localizado en el anillo periférico oeste del centro de la ciudad de Córdoba. En la actualidad, los adscriptos señalan que dicho nombre fue parte de una serie de prácticas y políticas de invisibilización del gobierno municipal y provincial hacia la comunidad indígena, siendo esta práctica parte culminante del proceso de expropiación y desalojo llevado a cabo a partir de la década de 1860. 
Territorio(s) e indigeneidad(es): aportes a partir del...

LUCAS PALLADINO

Debido a estos procesos, los comuneros que se reivindicaron como comechingones consideraron que rearticularían su comunidad, oculta y en silencio durante casi un siglo. Así, durante los primeros años sus prácticas se orientaron al reconocimiento social y legitimación de su identidad indígena, entre ellas, la organización social y política basada en la representación por curaca,${ }^{12}$ configurándose por siete representes familiares, la visibilización como originarios a escala local y el reconocimiento de la preexistencia étnica y territorial frente al Estado nación logrando, de hecho, obtener la personería jurídica del INAI en 2010.

En este contexto conflictivo participaron las argumentaciones de autenticidad -aquí sostenemos que el pasado territorial jugo un papel fundamental en la construcción de sentimientos de pertenencia en el proceso de comunalización de la Comunidad Comechingón del Pueblo de La Toma-. Seguimos a Hall (1996) para dar cuenta que el "afuera constituyente" es parte fundamental de todo proceso de identificación, de modo que las identidades son relacionales, contingentes y constituidas a través de estas relaciones de fuerza. En este contexto, es preciso entender que, al visibilizarse públicamente, la comunidad de La Toma se vio enfrentándose con voces locales, como la de un funcionario de la Junta Provincial de Historia de Córdoba, que sostenía:

(...) leí que mediante un estudio se ha identificado sangre aborigen en siete familias que habitan desde hace muchos años en barrio Alberdi de nuestra ciudad. Allí se afirma que el descubrimiento acredita su ascendencia comechingona, lo que me lleva a preguntarme sobre la base de qué patrones genéticos se llega a esa conclusión (...). No hay ninguna constancia documental de que en lo que hoy es el barrio de Alberdi hubiera un pueblo de indios a la fecha de la fundación de Córdoba. (Bustos Argañaraz, 2007).

Además, Argañaraz realizó algunas conferencias en barrio Alberdi, donde se enfrentó con comechingones que contraargumentaron su opinión. Como sostuvo Alberto luego de mostrarme su descendencia al curaca Lino Acevedo "este tipo dice que no éramos comechingones...y le salimos al cruce" (A. C, agosto de 2008). A la par, y como objeto de esta mirada, en presentaciones públicas los comuneros tendían a realizar un relato donde argumentaban que eran descendientes de comechingones que vivieron en el Pueblo de La Toma y tendían a narrar sus trayectorias familiares. Al presentarse, cada uno comenzaba marcando su ascendencia, mencionando el parentesco con algún "curaca" del siglo XIX. En ocasiones reiteradas, cada adscripto mencionaba los términos "silencio", "ocultamiento" o "invisibilización" para referirse a que sus familias habían vivido en la clandestinidad hasta el momento de su rearticulación. En este sentido, se presentaba la identificación genealógica con "curacas" y "comuneros" que habitaron el Pueblo y la alusión a la perdurabilidad o continuidad de esas familias en el "territorio de La Toma" hasta la actualidad.

Observamos la construcción de una historia que vincula a las familias con la comunidad de La Toma en el pasado y presente. En primer lugar, con el relato de una adscripta:

12 El curacazgo es el sistema de representación política que reivindican los adscriptos, cada curaca es el representante de una o varias familias. 
LUCAS PALLADINO

Como dice la historia que los comechingones vivían en clanes (...) claro vivían familias o, del mismo apellido, digámosle así, de la misma familia en grupo, y había un jefe, un curaca que manejaba todo ese grupo. Entonces yo ahora que, estoy descubriendo de acuerdo a los registros que han quedado en el Arzobispado y (...) en los documentos públicos, de que mi bisabuela lo tenía como un clan a su familia. Era tierra de ella y trataba de agruparlos a toda la familia (...) Estamos hablando de 300 años, 250 años atrás... eh... y, y al lado tengo una prima hermana, a la vuelta tengo otra prima hermana, a la otra vuelta y acá, o sea que ha quedado en menos cantidad, se han dispersado, pero ha quedado." (L., noviembre de 2009).

En segundo lugar, por los relatos narrados a nivel comunal, en lo relacionado con la desarticulación de dichas familias y la propia comunidad:

En la segunda mitad del siglo XVIII, trajeron hermanos diaguito-calchaquíes, pocos como para poblar la región. Y allí nació el argumento tramposo del sistema que nuestro pueblo venía del norte, que no éramos dueños de nuestra tierra. (...) Se sumaron otros, algunos hermanos pampas, afrodescendientes y blancos, pero el tronco principal nunca huyó, fuimos siempre nosotros, los comechingones $(\ldots)$

Queremos que Córdoba sepa que nunca nos fuimos, que siempre estuvimos aquí, preservando, en silencio, la memoria. Y que nos dimos cuenta de que es necesario trasmitirla, contarla, hacernos visibles por una cuestión de justicia (...). (Folleto de promoción de la Comunidad comechingona del Pueblo de La Toma, octubre de 2008:2, 5. Destacado en el original).

Entendemos a esta operatoria en el sentido que menciona Ana Ramos (2005) cuando utiliza el término "narrativas" en cuanto matrices de interpretación y selección de hechos del pasado que construyen la historia comunal. En este caso, se trata de una narrativa histórica territorial que instituye un relato cronológico y lineal ${ }^{13}$ del presente, estableciendo una continuidad con las prácticas del pasado, identificando especialmente diferentes períodos, eventos y hechos en los que indígenas, curacas y comuneros ejercían territorialidad en el Pueblo de La Toma.

Por un lado, los sentidos históricos operan aludiendo a una temporalidad que constituye períodos entre los cuales los adscriptos mencionan cinco para narrar su historia. El primero se denominó Territorio ancestral. Se trata del territorio antes de la fundación de la ciudad de Córdoba (1573), entonces habitado por diferentes grupos indígenas (Chiliznas, Cantacaras, Suquías, Siquiman, entre otros) previos a la reducción del Pueblo de La Toma. El segundo (1573-1880) se denominó Primera reducción del Pueblo de La Toma y trata del territorio comechingón posterior a la fundación de la ciudad. En este apartado se hace referencia a la llegada de los españoles y la correspondiente

13 En este caso, del Pueblo de La Toma aparece la versión cronológica y lineal como modo de enunciación del pasado. Esta versión, como veremos, se construye en la articulación con fuentes históricas. En todo caso, la selección de hechos del pasado consta de "materiales optativos, a disposición de las comunidades que pueden, estratégicamente y de acuerdo a los procesos de unidad o diferenciación -al menos- poner de relieve determinados énfasis, acentuar posicionamientos, o reordenar por completo esas narrativas. 'El tiempo es, en definitiva, un material usado para significar"' (Martínez 2010:68 en Boullosa y Rodríguez, 2004:16. Destacados de las autoras). 
Territorio(s) e indigeneidad(es): aportes a partir del...

LUCAS PALLADINO

esclavización de indígenas y reducción al territorio del oeste. El tercer período (1880 a 1910) lo titularon Segunda reducción, expropiación y resistencia del Pueblo de La Toma;se representa la reducción del territorio de La Toma tal como figura en el catastro Machado (con la correspondiente señalización de lotes, manzanas y trazado de calles). El período cuatro, comprende desde el año 1910 hasta 2007 y lo titularon Invisibilización y ocultamiento; se representan los espacios ocultos de la identidad comechingona (espacios privados donde se transmite la memoria oral) y al mismo tiempo se muestran las prácticas simbólicas del Estado que pretendieron invisibilizar a los comechingones (transmisión de identidad nacional en la educación pública). En este sentido, ellos expresan que: "no sólo nos sacaron tierras, sino que nos quisieron borrar del mapa cambiándonos nombres, calles y el mismo barrio. Pero resistimos, nunca huimos, nos quedamos en el espacio privado, manteniendo nuestra identidad en secreto, al interior de nuestras casas" (H.A., setiembre de 2017). Finalmente, el quinto período es a partir del 2007- 2008 y lo denominaron Rearticulación de la comunidad y visibilización. Se trata del reencuentro de los comuneros y las actividades y acciones que llevaron a cabo desde entonces.

Lo anterior puede observarse en la siguiente línea de tiempo que la comunidad realizó a partir de un mapeo colectivo y colaborativo que propuse durante el trabajo de campo.

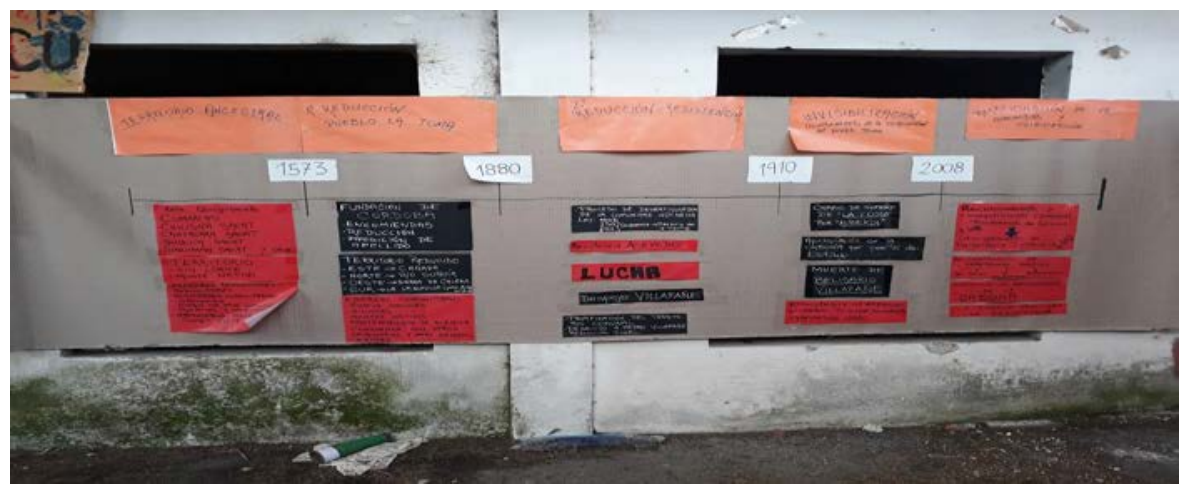

Figura 3. Línea de tiempo construida por los comuneros en el marco de las jornadas de mapeo colectivo. Fuente: autoría propia.

\section{Construyendo el territorio ancestral: entre los mapas catastrales y el mapeo colaborativo}

Un aspecto destacado en conversaciones, entrevistas y presentaciones de los adscriptos era su identificación con curacas del Pueblo de La Toma y la asociación de su pertenencia por haber nacido en el territorio ancestral. En reiteradas ocasiones han expresado: "Nosotros somos comechingones del Pueblo de La Toma porque nacimos acá" (T.V., octubre de 2008). Al decir "nosotros somos comechingones" (en términos de pertenencia étnica) aparece, seguidamente, la aclaración, “del Pueblo de La Toma” (aspecto territorial) y, a veces, el argumento: "porque nacimos acá" y/o "porque siempre vivimos acá" (continuidad genealógica). El "acá" hace referencia a una localización física que se delimita dentro de los márgenes del antiguo Pueblo de La Toma, cuyos límites son indicados superando la delimitación municipal de Pueblo Alberdi. Asimismo, el "acá" refiere a este espacio habitado que también se concibe previo a la fundación de la ciudad de Córdoba. En este sentido, en el "acá" operan tanto las memorias territoriales 
LUCAS PALLADINO

de la reducción (el Pueblo de La Toma) como la preexistencia territorial a la ciudad; ambas configuran encuadres o marcas espaciales que fijan los sentidos comunales en el pasado y le dan sentido al presente.

En este contexto, la utilización de la cartografía catastral histórica ha sido fundamental para el proceso de identificación indígena y construcción del pasado primordializado. Por medio de planos del siglo XIX se evidencia la existencia de la comunidad de La Toma (por ejemplo, en un plano del año 1882) y luego para 1888 el mapa titulado "División de terrenos del pueblito". Cabe aclarar que, simultáneamente, se estudiaron documentos periodísticos, títulos y diferentes fuentes que muestran la desarticulación de la comunidad para finales del siglo XIX, cuando existió en Córdoba un marcado avance en los loteamientos y en la compra de tierras por parte de la elite urbanizadora y el Estado liberal (Boixadós, 2006). A través de esta selección de cartografías los comuneros buscan constatar que sus apellidos, como también algunas de sus propiedades, aparecen en el catastro. De esta manera se constata la antigüedad de las familias en el territorio y la posesión de tierras, otorgando así legitimidad a la existencia de la comunidad de La Toma en el pasado, ya que a través de ella se muestran los sectores pertenecientes a la comunidad de La Toma.
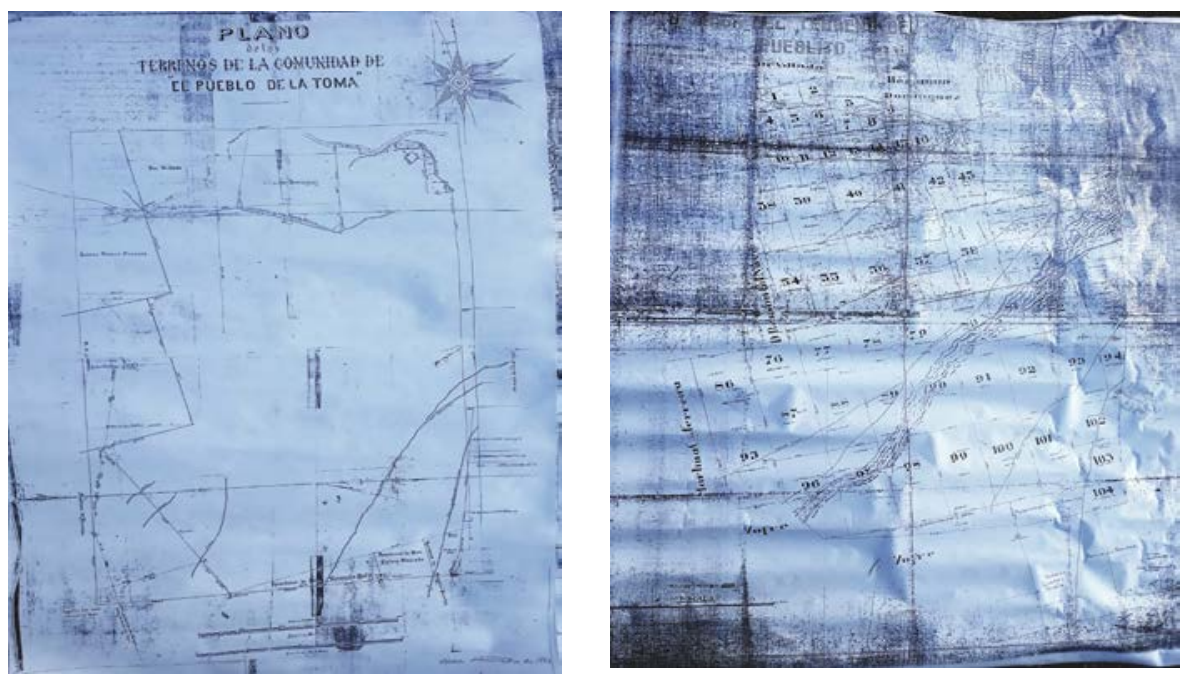

Figura 4. Plano de los terrenos de la comunidad El Pueblo de La Toma, 1882 (izq.) y plano de división del terreno del Pueblito, 1888 (dr.). Fuente: Reproducido de Palladino, 2020.

Puede observarse, también, la construcción del territorio ancestral o ancestralización del territorio (Martínez Berrios, 2015) en los sentidos que existen sobre el territorio histórico, definido por la línea del tiempo (Figura 3) y articulados con los planes catastrales que muestran la paulatina reducción y división de tierras de La Toma (Figura 4). En la construcción de los talleres que realice ${ }^{14}$ acompañamos el proceso con un mapeo

14 Se trató de talleres llevados a cabo durante los meses de agosto y setiembre del 2017, en el marco de mi investigación doctoral. En esta instancia participaron algunos miembros de la Comunidad Comechingón del Pueblo de La Toma, vecinos, miembros del Instituto de Culturas Aborígenes e integrantes del Centro Vecinal de Barrio Alberdi. 
LUCAS PALLADINO

colectivo y colaborativo (Ares y Risler, 2013; Ascerald, 2013) (15 $^{15}$ que representaba los cinco períodos en la historia del territorio de La Toma. Aquí, los comuneros pretendían representar acontecimientos claves en la historia del despojo, actividades económicas, cosmovisión, usos de la tierra, entre otros. Para eso utilizaron los mapas catastrales (entre otras fuentes como libros y títulos de tierras) que permitieron mapear los límites del territorio de La Toma y visibilizar las prácticas de expropiación, reducción y desarticulación de la comunidad en el siglo XIX.

Identifiqué que de los cinco períodos mencionados más arriba, los comuneros enfatizaron las acciones y procesos que se dieron a lo largo del tercer período, interviniendo en el mapa todas las prácticas de desterritorialización (expropiación, despojo, invisibilización). Como se observa en la Figura 5, en el mapa de La Toma se representaron las acciones de expropiación con símbolos de prohibición (de la vida comunitaria, de uso del espacio público, de las actividades comunitarias). Se enfatiza el período que ellos reconocen como de ruptura oficial cuando se ejecuta la Ley de Desarticulación de Comunidades (1885), ${ }^{16}$ se observan íconos que muestran el accionar de la justicia (martillos) y la policía (escudos), la línea del ferrocarril y la cuadricula urbana en su territorio
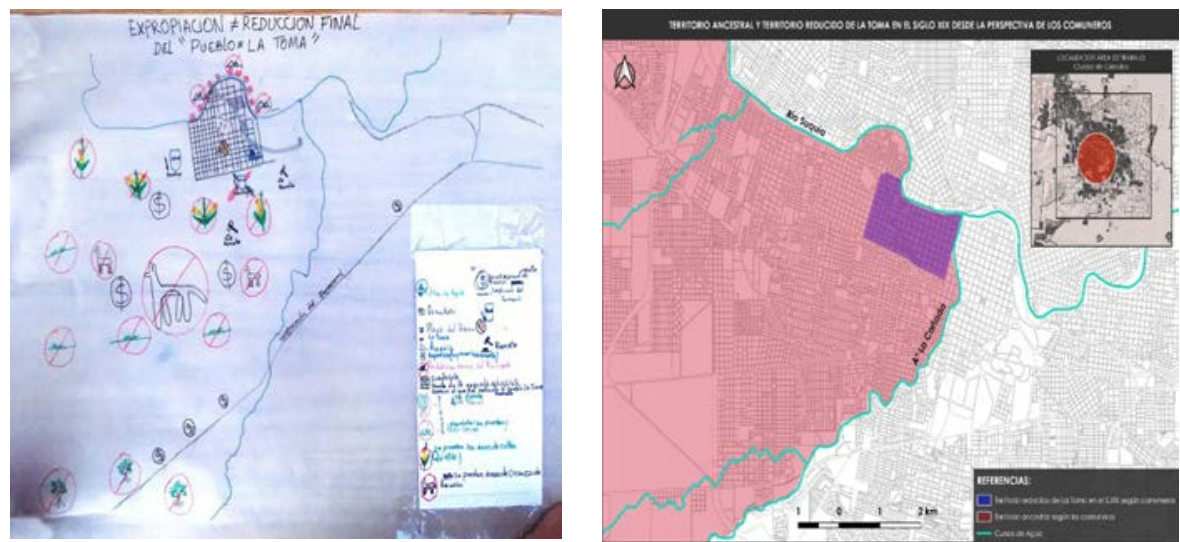

Figura 5. Mapa realizado por los comuneros del período tres, titulado "Expropiación y reducción final del Pueblo de La Toma" (izq.) y referencia del territorio del Pueblo de La Toma evocado por los comuneros (sombreado rosa, territorio ancestral; sombreado violeta, la reducción de siglo $X I X)(d r$.$) . Fuente: Palladino, 2020$.

Se observa que a través de la construcción de narrativas sobre el pasado territorial, los adscriptos fortalecen su identidad comunal en el presente y, además, disputan sentidos sobre la invisibilización comechingona, de manera que construyen un relato que permite otorgar autenticidad en un contexto considerado de extinción aborigen. Se ha dado cuenta cómo los sentidos implicados en la comunalización se construyen a partir de la reinvención de la tradición y desde la perspectiva de la primordialización de los vínculos. Así, el pasado territorial permite naturalizar los vínculos con el pasado

15 Se entiende al mapeo colaborativo como "una instancia a partir de los cuales se pueden favorecer las distintas formas de comprender y señalizar el espacio a través del uso de variados tipos de lenguaje, como símbolos, gráficas e íconos, que estimulan la creación de collages, frases, dibujos y consignas" (Ares y Risler, 2013:6).

16 Esto se debe a la aprobación de las leyes de desarticulación y expropiación de comunidades (años 1882 y 1886) que llevaron a la prohibición del uso de espacios a los comuneros, la subdivisión de los terrenos de la comunidad del Pueblo de La Toma, y desencadenaron en remates y desalojos. Dicha subdivisión acabaría materializándose finalmente en 1909 con la creación de barrio Alberdi. 
Territorio(s) e indigeneidad(es): aportes a partir del...

LUCAS PALLADINO

y visibilizar las rupturas producidas en la comunidad, particularmente a efecto de las políticas del Estado colonial y republicano (en sus diferentes escalas) y sus modos de territorialización (Pacheco de Oliveira, 2010). En este contexto, los mapas catastrales visualizan el poder (Harley, 2005) y las estrategias dominantes de territorialización, y su uso contemporáneo permite dar cuenta de cómo el mapeo construye a la cartografía como instrumento contrahegemónico (Arias, 2010).

Así, a través de las diferentes prácticas de construcción del pasado territorial que observamos, se ponen de manifiesto las oposiciones o contrastes (Cardoso de Oliveira, 2007) de las atribuciones y valoraciones de la comunidad frente a las prácticas ajenas. Estas oposiciones se asocian a la práctica de diversos agentes gubernamentales y empresarios, asociados con la organización territorial del Estado moderno. En el marco de estas oposiciones los adscriptos interpretan las prácticas de estos otros como propias de la vida urbana, moderna y capitalista, y contrarias a un nosotros inscripto en el territorio comunal. Es precisamente la alusión a diferentes períodos de tiempo donde se considera que la expropiación, el avance de la urbanización sobre el Pueblo de La Toma y la invisibilización de la comunidad son procesos que participaron en un forzoso intento de desterritorialización.

\section{El territorio como lugar de encuentro y devenir indígena: la Comunidad Comechingón Ticas}

En el año 2009 un grupo de personas que se identificaron como indígenas comechingones oriundos de la localidad de San Carlos Minas (departamento homónimo, al noroeste provincial) decidieron rearticular la Comunidad Comechingón Ticas y obtuvieron el reconocimiento de la personería jurídica del INAI. Se trató del primer reconocimiento oficial por parte de las agencias estatales hacia una comunidad indígena en Córdoba. Luego de obtener la personería, los adscriptos Ticas, entonces residentes en diferentes espacios de la provincia de Córdoba (Córdoba, Carlos Paz, San Carlos Minas), decidieron ocupar unas tierras ubicadas en el sector de Rosa Mística en Bialet Massé, Valle de Punilla. A razón de la figura de la ocupación tradicional de las tierras indígenas, ${ }^{17}$ los Ticas hicieron posesión del territorio.

Según la memoria oral comunitaria, estas tierras les pertenecían por razones históricas ya que aquí se localizaron las familias de descendientes del pueblo comechingón Ticas. Así, ubican una presencia milenaria ancestral y un origen en la localización de su comunidad en la zona de San Carlos Minas. Allí se sostiene que el pueblo fue desagregado y fracturado tras la ocupación de la colonia española, siendo sus descendientes reducidos, en parte, a los pueblos de indios próximos en la región y dispersos a otros sectores de la provincia como fuertes y estancias. Entre estos lugares los Ticas destacan

17 A partir del Artículo No 75, Inciso 17, de la Constitución Nacional, emergen las discusiones sobre el reconocimiento jurídico de la posesión y la propiedad comunitaria. Aquí aparece la cuestión sobre la ocupación tradicional de las tierras, entendida como una forma cultural de territorialidad diferente de la propiedad privada. A su vez, las comunidades sostienen que existen otras maneras de ocupar y hacer uso del territorio, apelando a la vinculación con sus geografías y a las memorias históricas sobre los lugares. Estas discusiones fueron tomadas en cuenta luego, a partir de la sanción de la Ley №26.160 sobre "emergencia en materia de posesión y propiedad de tierras que tradicionalmente ocupan comunidades indígenas". Fuente: https://www. desarrollosocial.gob.ar/wp-content/uploads/2015/08/6.-INAI-Tierras-y-registro-nacional-de-comunidadesind--genas.pdf 
LUCAS PALLADINO

sectores como Villa Carlos Paz, Cosquín y Bialet Massé. En el proceso algunos de ellos fueron trasladados a Cochatalasacate y alrededores, lugar al que reconocen y reivindican como propio en Bialet Massé. Los adscriptos consideran que este terreno es parte de una gran área de vinculación con San Carlos Minas (que en términos latitudinales se encuentra a 50 kilómetros) y hace parte de una "gran zona arqueológica" evidenciada a través de objetos, morteros, pictografías, entre otros.

El pasado territorial de la comunidad fue configurado a partir de identificar su ligación y control territorial en San Carlos Minas y las diásporas de los indígenas hacia otras zonas de la provincia. De este modo, las memorias geográficas, conjuntamente al trazado de las genealogías con ancestros que ocuparon estos espacios, trazaron los primeros argumentos de la territorialidad Ticas en su proceso de comunalización contemporáneo.

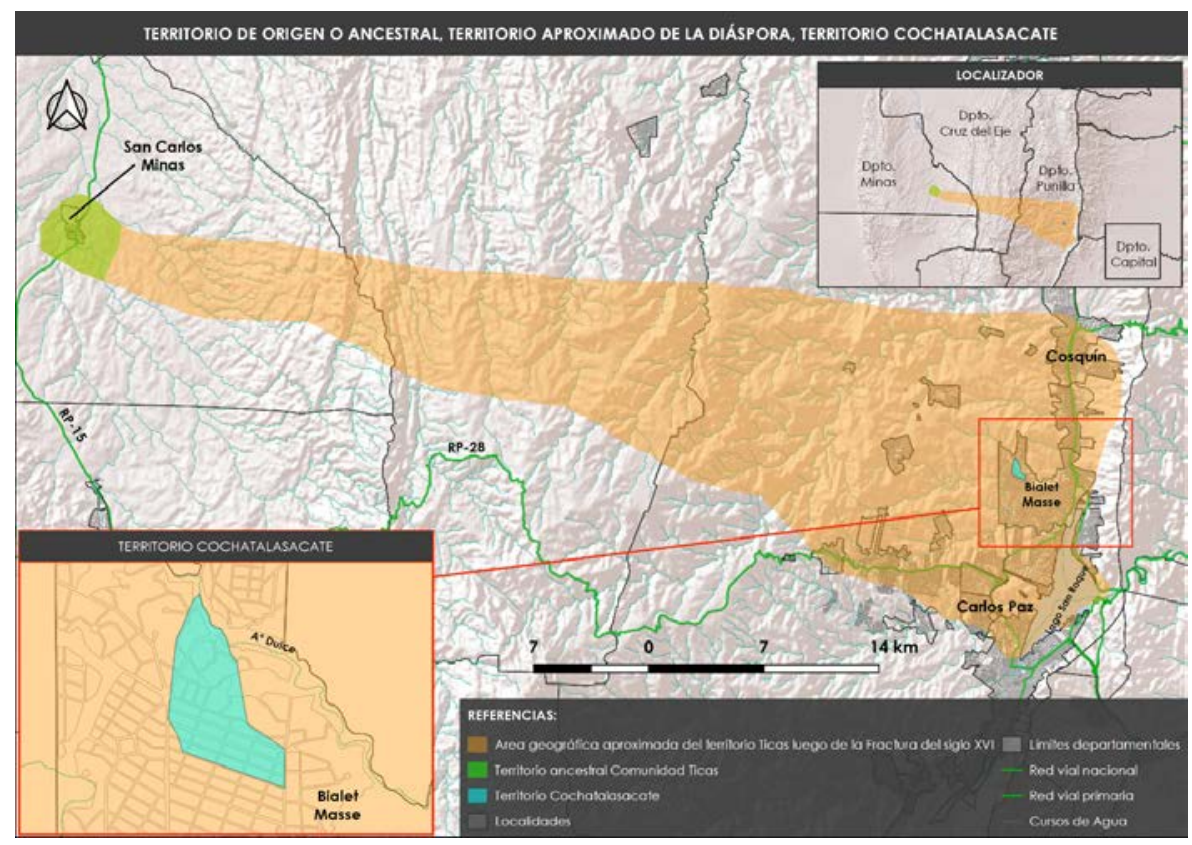

Figura 6. Territorio Ticas. Fuente: cartografía realizada por Oscar Vives. Palladino, 2020.

Así, los Ticas configuraron un relato del pasado en el que la desterritorialización jugó un papel fundamental para la desarticulación comunal, siendo esa apelación al desplazamiento lo que otorgó un sentido a la vuelta en la actualidad en el espacio delimitado de Cochatalasacate. Así, volver a ocupar las tierras de Cochatalasacate implicaba no un desplazamiento a un lugar nuevo, sino más bien un proceso de re-territorialización y de reconstrucción comunitaria en su lugar de pertenencia. Esto jugó un papel central en la identificación comunal Ticas, en la medida en que aparece la primordialización como componente clave de la comunalización.

\section{Construyendo Cochatalasacate}

Luego del proceso burocrático de personería jurídica, los Ticas se reorganizaron para empezar a construir la infraestructura necesaria para habitar el territorio, hasta entonces rodeado de monte nativo. En un período de reorganización comunal que implicó la 
Territorio(s) e indigeneidad(es): aportes a partir del...

LUCAS PALLADINO

manifestación de emociones y anhelos, los Ticas sintieron que podían hacer un sueño posible:

Lo estamos haciendo posible... un largo anhelo de la comunidad era lograr plasmar en la tierra que nos cobija un deseo, una necesidad, un sueño... el de poder darle forma material al espacio que nos reunirá por generaciones, donde compartiremos y celebraremos, donde nos miraremos en silencio como hermanos de esos árboles, de esas flores, de esas piedras... en tiempos de la conquista nuestra comunidad fue fracturada, algunos quedamos en el territorio de San Carlos Minas custodiando los sitios sagrados y la propia vida, otros fuimos llevados a distintos lugares de nuestra provincia, aquí... en Cochatalasacate también fuimos familia y estamos volviendo a ese seno materno. (...) poder de plasmar una intención en esa acción, de crear nuestro entorno a la vez que somos creados a diario por él, armónicamente y en equilibrio con la Madre Tierra. (T., marzo de 2013).

El relato anterior muestra la inauguración de una etapa de volver a la comunidad aborigen. Como se sostuvo, implicaba ocupar el territorio ancestral con la intención de crear un entorno propicio para vivir comunitariamente. Estas acciones constituían la expectativa de llevar a cabo la considerada vida comunitaria en el futuro y de plasmar ahí las acciones que entendían como la de los pueblos originarios. Entre ellas cobraron un especial énfasis las recurrencias enunciativas a la espiritualidad y el concepto de buen vivir. Este último, como veremos, estuvo asociado a la perspectiva de vivir armónicamente con el entorno: "el Buen Vivir/Bien Vivir representa en nuestras comunidades una regla sagrada donde en base a simples y poderosos principios buscamos vivir en armonía y paz con nuestro entorno natural y social" (Boceto de Taller Construir Construyéndonos. Comunidad Ticas, marzo de 2013).

Estos supuestos eran leídos en clave de analogías con los modos de vida comechingón del pasado. Como sostuvo Aldo, adscripto Ticas, la experiencia de vivir en el territorio era la experiencia comechingona del "sacate". Como en una oportunidad les pregunté “¿Un sacate?” A lo que respondieron "Si, como un pueblo pero que en realidad no es un pueblo como los de ahora, es algo más...como una comunidad”. Así, los sentidos comunitarios implicaron una serie de prácticas consideradas alternativas.

Aquí no sólo emergía como objeto de interés el pasado comunitario. De hecho, al preguntarles sobre ello los comuneros destacaron que la importancia del ser indígena trataba del presente y el futuro, y que por ende la comunidad era una comunidad de acción. Por su parte, las reuniones pregonaban una ocupación del territorio bajo el lema de construir allí los principios del buen vivir. Así, lejos de caracterizarse la comunidad como un lugar habitado solamente por adscriptos comechingones, también aparecían una decena de amigos, residentes en las sierras, universitarios, organizaciones, ONG (actores sociales vinculados a la lucha contra el desmonte, el agronegocio, la soberanía alimentaria) y artistas. Ellos contribuyeron a la lectura de la organización del territorio y a la construcción material a través del dictado de talleres, cursos y jornadas de trabajo colectivo como mingas. Por otro lado, los Ticas planearon una serie de eventos culturales y prácticas ceremoniales en el territorio como el Inti Raymi, la celebración de la Pachamama y el evento cultural Festivaleando en el Monte en el cual los objetivos eran reconocerse e intercambiar principios y experiencias con otras culturas. En la medida que estas nociones de la experiencia comunitaria compusieron 
Territorio(s) e indigeneidad(es): aportes a partir del...

LUCAS PALLADINO

un papel clave en la reconstrucción del territorio, sostuve que dicha experiencia podía ser interpretada con la categoría "communitas" de Víctor Turner. ${ }^{18}$

\section{Devenir Ticas: entre la communitas y el "idilio rural", entre lo local y lo global}

La ocupación de Cochatalasacate implicó así un período marcado por las representaciones culturales del ser indígena/Comechingón, trayendo a colación y materializando en el territorio esquemas concebidos sobre la indigeneidad basados, en primer lugar, en una particular lectura de las prácticas del buen vivir como un modo de vinculación espiritual a la madre tierra ${ }^{19} \mathrm{y}$, en segundo lugar, a la noción de lo comunitario en tanto espacio de intercambios, experiencias y encuentros en la naturaleza. Entiendo que estos sentidos se relacionan con las trayectorias socioculturales de los adscriptos, siendo vinculadas a lo que Julieta Quirós (2014) entiende como los procesos de neo-ruralismo o neo-ruralización. Estas trayectorias representan nuevos procesos migratorios de ciudad-campo que buscan un modo de vida en contacto en la naturaleza, pero también ciertas valorizaciones sobre lo rural, como la posibilidad de conectarse con un entorno natural rodeado de monte nativo, de prácticas agro-ecológicas y sustentables. En esta línea, David Bell (2006) sostiene que algunas prácticas construidas en entornos rurales presentan el "idilio rural" como una romantización de las actividades del campo que es consecuencia de la expresión de la clase media urbana que busca vivir en dicho espacio.

En otra oportunidad mostré como la Comunidad Ticas va construyendo su proceso de territorialización en Cochatalasacate enrolando la memoria oral con una serie de valorizaciones morales sobre el estar en el campo (Palladino, 2017). En primer lugar, puede observarse la participación de actores no indígenas, pero con una preocupación fuertemente espiritual y new age, como la figura un comunero que diagramó un plan arquitectónico basado en la sabiduría Maya. ${ }^{20} \mathrm{Al}$ respecto, una líder comunitaria explicó que el territorio estaría compuesto por ocho casas que conformaban un sistema octogonal cuya geometría era consecuente con los ocho rayos primarios del Inti (sol) Comechingón:

Esto es parte de una construcción de un octógono... [Muestra] hacia el centro, es lo que va a ser el patio central de ese octógono. Este octógono representa al sol comechingón, tiene ocho construcciones y ocho calles, de acuerdo a los 16 rayos que tiene el sol del Pueblo Comechingón. Como es un símbolo de fuego, y es un símbolo activo, al centro de este patio habrá un lugar de ceremonia para que sea el espíritu de Pachacama, el dios creador de todo, el que nos guie, y

18 Turner (1988) denominó como communitas al momento de percepción, disrupción y transgresión de las estructuras hegemónicas que inspira sentimientos de camaradería y unión entre quienes se sienten pertenecientes a un grupo.

19 Para Valhust y Belling (2013) el término Buen Vivir o Vivir Bien aparece en la década del 1990 a partir de la conjunción de tres factores: la actuación de los movimientos indígenas, los movimientos antiglobalización y el desencantamiento con los modelos de desarrollo. La idea del buen vivir expresa la "reelaboración contemporánea del concepto quechua "Sumaq Kawsay" y conceptos afines de otros pueblos autóctonos" (2013: 1) En particular, remarca tanto la idea de interdependencia de la sociedad y su medio ambiente natural como la concepción de lo "universal como realidad pura".

20 En la actualidad es posible identificar ciertos vínculos entre la idea de "ciencia maya", las representaciones new age y la emergencia de ciertas representaciones indígenas como el romanticismo del buen salvaje rousseriano, la ética anticapitalista, la preocupación por el medio ambiente, la crítica a la cultura del consumo y del individualismo (Tally, 2012). 
Territorio(s) e indigeneidad(es): aportes a partir del..

LUCAS PALLADINO

el que sea testigo del intento, y de las ganas de nuestro corazón de ir hacia un mundo mejor, más humano, más vivible, donde podamos plasmar el sueño de los pueblos, de volver a vivir comunitariamente. (T., marzo de 2013).

En segundo lugar, la realización de una serie de prácticas de reforestación que traen consigo la consigna de interpretarse como guardianes del monte, en una asociación que los coloca como "nativos ecológicos" (Ulloa, 2005) asociando a la comunidad indígena con una serie de valores relacionados con la sustentabilidad ambiental, el cuidado de la naturaleza y la vida armónica comunitaria.

Un episodio sucedió en 2015, cuando una empresa desarrollista intentó ocupar parte de las tierras Ticas. Se trataba de un emprendimiento privado denominado Valle Esmeralda que buscaba realizar allí un country. La empresa había avanzado deforestando vegetación, tirando alambrados y también construyendo parte de los cimientos de algunas residencias. Los comuneros Tica respondieron al accidente enunciando más la preocupación por la deforestación de Bosque Nativo presente, que organizando el reclamo por su justo motivo de ocupación histórica ancestral. ${ }^{21}$ En este sentido, lo interesante es que la enunciación del papel de la comunidad en el cuidado del monte nativo es la que le dio el lugar central en el discurso comunitario. Por su parte, los comuneros decidieron realizar una serie de acciones tendientes a recuperar dicho monte, expresando que el territorio de la comunidad era "territorio de preservación del monte nativo".

Ayer recibimos noticias de que habían cercado parte del territorio ticas y que además de eso entraron a abrir caminos con una topadora destruyendo así nuestro monte nativo, el cual cuidamos, protegemos y amamos (...) llamamos a toda la gente que quiera solidarizarse con nuestra causa, la causa de la vida, de la preservación del monte nativo, no dejemos que avancen más (...) la pacha es de todos, y entre todos debemos defenderla!!!! (Comunicado de la Comunidad Ticas en la red social "Facebook". 29 de abril de 2015).

En tercer lugar, el avance de la empresa desarrollista también reposicionó los discursos ecológicos comunitarios. Ello aparece en una serie de prácticas que la comunidad realizó durante años, y que se vieron afectadas por el entorno natural. Esto se aprecia en la construcción de un mapa que realizó un tesista con integrantes comunitarios. Aquí se ubica al territorio como parte integrante de la propia comunidad. En la siguiente figura se aprecia la consideración del monte como parte fundamente de lo comunitario, y el habitar indígena en mutua implicancia con el monte nativo.

21 Estas preocupaciones se articulan con un contexto local de reivindicaciones de la Ley de Bosques de la Provincia de Córdoba, donde diversas organizaciones sociales reivindicaron el cuidado del bosque nativo provincial, entonces reducido a un $4 \%$. 




Figura 7. Mapa del territorio Cochatalasacate elaborado por comuneros en un mapeo colectivo. Fuente: cortesía de Martín Formía.

Apoyándonos en las concepciones nativas sobre el territorio, entendemos que estas representaciones sobre la pertenencia comunitaria e indígena también son configuradas por los discursos habilitados sobre el ser indígena en la actualidad. Enunciados como "madre tierra", "Pachamama", "buen vivir" y prácticas que pujan por la construcción de una relación armónica de la comunidad con el entorno dan cuenta de tipos de valorizaciones sobre la indigeneidad que construye la comunidad en su proceso de re-territorialización. Así, la indigeneidad Ticas se construye en la articulación de una serie de enunciados regionales, interpretaciones new age sobre lo comechingón, que se materializan en el territorio apropiado y dominado de Cochatalasacate. En este sentido, el monte nativo y la preocupación por devenir sus guardianes aparece como elemento de identificación y pertenencia comunal que emerge en las mismas prácticas de territorialización de Cochatalasacate. El territorio se inscribe como el ámbito de reunificación, como lugar de encuentro, de trayectorias y representaciones donde la indigeneidad Ticas, la communitas, es posible de consumarse.

\section{A modo de cierre}

A nivel general el caso comparativo posibilita entender las diversas tramas en las que se movilizan sentidos de pertenencia en grupos comechingones comunalizados en espacios urbanos y rurales de Córdoba. Así, este tipo de investigación permite ver cómo la identificación indígena se construye como efecto y articulación de las relaciones históricas e interétnicas, y el lugar que ocupa el territorio a nivel simbólico-afectivo y en las prácticas espaciales. 
En primer lugar, en cada caso se observa cómo el proceso de comunalización no se limita a la coyuntura de institucionalización de la comunidad, sino que los sentidos son movilizados y operan permanentemente de forma activa. En el caso de La Toma, identifico la primordialización de pasado territorial como estructurante de las pertenencias, tanto al interior como en el proceso hacia el exterior, involucrando las acciones de visibilización y las prácticas políticas-territoriales. En el caso de los Ticas, observo que los sentidos vinculados a la primordialización se estructuran sólo en las narrativas de comuneros y que estos relatos se enfatizaron en el proceso de institucionalización y obtención de personería jurídica. En consecuencia, los sentidos de la comunidad como communitas y nativos ecológicos fueron aquellos que movilizaron las pertenencias en el período de investigación.

En segundo lugar, puede apreciarse cómo las coyunturas políticas, territoriales y las relaciones interétnicas que atravesaron a las comunidades se relacionan con la movilización de los sentidos de pertenencia comunitarias.

A partir de ello, en tercer lugar, se produce simultáneamente la construcción performativa de las comunidades y el territorio. Pues no sólo el territorio es resultado de la construcción de los sentidos movilizados en la comunalización, sino que las pertenencias son también activadas en las prácticas, performances que involucran la espacialidad y los procesos de territorialización. El territorio es construido performativamente en ambas comunidades, pero también los sentidos que se movilizan en base a lo que Dorien Massey (2008) llama la "multiplicidad de trayectorias". Diferentes trayectorias sociales y culturales convergen en la territorialización Ticas y, como espacio de la multiplicidad y diferencia, habilitan los escenarios para la movilización de sentidos de pertenencia indígenas.

¿Cuáles son entonces esos sentidos construidos? En la Toma se construye un proceso de territorialización que crea al Pueblo de La Toma como territorio. Pero la reemergencia indígena es producida como efecto de las políticas estatales de invisibilización y de la urbanización del territorio. En efecto el territorio construido de La Toma atiende a estos juegos de invisibilización simbólica y desterritorialización material. La comunalización de La Toma enfatiza los sitios conmemorados, estableciéndose como lugares de memoria que confrontan la narrativa oficial y los criterios de autenticidad. Estos sitios habilitan escenas y discusiones que retroalimentan las prácticas. Comuneros refuerzan el pasado, las prácticas culturales y los modos legítimos para ceremonializar y actuar como comechingones. En este contexto, portavoces aparecen y ofician propiciando epistemologías y metodologías de investigación históricas. En ese juego el proceso constituye una re-territorialización simbólica y material de La Toma en barrio Alberdi.

La comunidad Ticas construye el territorio ancestral como la gran área que conecta sierras, valles y tres departamentos (Punilla, Cruz del Eje y San Carlos Minas), apelando a las memorias ancestrales de desestructuración y fractura. Sin embargo, la reterritorialización Ticas se confina y estabiliza en el área geográfica de Cochatalasacate. El territorio habitado por monte nativo habilita la llegada de una heterogeneidad de trayectorias que confluyen en el espacio propicio de la indigeneidad: el monte. En un pliegue de significados entre Ticas y outsiders (militantes, new agers, jipis y bohemios), el monte convierte a Cochatalasacate en el espacio propicio para las actividades asociadas al ideal rural de la comunidad indígena: la del nativo ecológico. Ahora bien, estas 
Territorio(s) e indigeneidad(es): aportes a partir del... LUCAS PALLADINO

prácticas no son consecuentes con representaciones culturales acerca de los modos definidos hegemónicos sobre la indigeneidad, por el contrario, los eventos y prácticas culturales y territoriales nos dejan una enseñanza acerca de que la indigeneidad se puede expresar como una fuerza potencial. Así, las celebraciones Ticas no responden únicamente a las exigencias de autenticidad sobre un pasado territorial; las prácticas buscan constituir y configurar que el ser comunidad es inscribirse en un espacio de comadrería en la experiencia que implica el estar o acabar juntos afectivos.

Las prácticas performativas van volcándose al deseo de extraer la indigeneidad de otro modo, de otra manera, para, al menos, tensionar los sentidos hegemónicos instalados localmente. Así los comechingones nos muestran que en los procesos de re-territorialización también se crean territorios vívidos y afectivos que construyen otros sentidos al de los manuales y formulas arquetípicas de la comechingoneidad.

Por otro lado, sigue siendo importante seguir monitoreando y registrando los marcos políticos que habilitan a la construcción de narrativas, gramáticas y vocabularios legales y simbólicos que afectan a los procesos de comunalización comechingón en Córdoba. Esto debe investigar las diversas tramas y redes que constituyen las esferas de las agencias gubernamentales y políticas que habilitan los territorios y las comunidades comechingonas cordobesas.

Una línea presentada en los abordajes del territorio e indigeneidad más arriba fue la del campo de las ontologías políticas. Esto permite pesquisar la construcción de territorios indígenas en las tensiones epistémicas y ontológicas con las lógicas racionales y gubernamentales modernas. Así estos abordajes permitirían ver cómo se enarbolan humanos y no humanos en los procesos de construcción de mundos o entidades. Otros estudios sobre la comunalización, territorio e indigeneidad podrían explorar la articulación de estas perspectivas, teniendo en cuenta el recaudo de problematizar el papel de los conflictos, las relaciones de poder en el que se sitúan los sentidos y las relaciones interétnicas. 


\section{Q Bibliografía}

》 Acselrad, H. (2013). Cartografia social, terra e território. Río de Janeiro: IPPUR/ UFRJ.

" Appadurai, A. (1996). Sovereignty without territoriality: notes for a postnational geography. En P. Yager, P. (Eds.), The Geography of Identity (pp. 40-58). Ann Arbor: The University of Michigan Press.

》Ares, P. y Risler, J. (2013). Manual de mapeo colectivo: recursos cartográficos críticos para procesos territoriales de creación colaborativa. Buenos Aires: Editorial Tinta Limón.

》Arias, S. (2010). Mapeo autónomo y defensivo en la Zonal Pewence. 4tas Jornadas de Historia de la Patagonia, Bariloche, Universidad Nacional de Comahue.

» Badie, B. (1995). La fin des territories. París: Fayard.

" Barros, L. (2000). Reflexiones sobre la relación entre lugar e identidad. Documents d'Anàlisi Geogràfica, 30, 81-94.

» Bell, D. (2006). Variations on the rural Idyll. En P. Cloke, T. Marsden y P. Mooney (Eds.), Handbook of Rural Studies (pp. 94-108). [Traducción de la Cátedra de Geografía Rural, Departamento de Geografía, Facultad de Filosofía y Letras, Universidad de Buenos Aires].

" Bidaseca, K. (2010). Perturbando el texto colonial. Los estudios (pos) coloniales en América Latina. Buenos Aires: Ed. SB.

»Boixadós, C. (2006). Las representaciones cartográficas de la Ciudad de Córdoba. Entre 1870 a 1930. En C. Lois (Coord.), Imágenes y lenguajes cartográficos en las representaciones del espacio y del tiempo (pp. 17-26). I simposio iberoamericano de historia de la cartografía. Universidad de Buenos Aires.

» Bompadre, J. (2016). (Des)Memorias de La Docta. De barbudos miscegenados a comechingones comunalizados: procesos contemporáneos de emergencia étnica en Córdoba. Tesis de doctorado en Ciencias Antropológicas. Facultad de Filosofía y Humanidades, Universidad Nacional de Córdoba, Córdoba.

》 Boullosa-Joly, M., y Rodríguez, L. (2014). Fuentes etnográficas e históricas: repensando la relación entre pasado y presente. el caso de la comunidad indígena de Amaicha del Valle (Tucumán). Memoria Americana. Cuadernos de Etnohistoria, 22(2),43-66.

» Briones, C. (2005). Formaciones de alteridad: contextos globales, procesos nacionales y provinciales. En C. Briones (Comp.), Cartografías argentinas: políticas indígenas y formaciones provinciales de alteridad (pp. 11-44). Buenos Aires: Antropofagia.

" Briones, C. (1998). La alteridad del "cuarto mundo". Una deconstrucción antropológica de la diferencia. Buenos Aires: Ediciones del Sol.

»Briones, C. y Ramos, A. (2010). (2016). Agenciando formas de ser juntos en contextos interculturales: anudamientos de memoria, parentesco y política. En C. Briones y A. Ramos (Comps.), Parentesco y política. Topologías indígenas en la Patagonia (pp. 11-52). Viedm: Ed. Universidad Nacional de Río Negro. 
»Brow, J. (1990). Notes on Community, Hegemony, and Uses of the Past. Anthropological Quarterly, 63(1), 1-6.

»Brown, M. (2010). Tradiciones de la soberanía. En M. de la Cadena y O. Starn (Eds.), Indigeneidades contemporáneas: cultura, política y globalización (pp.191217). Lima: Editorial IEP.

» Bustos Argañaraz, P. (25 de Octubre de 2017). No eran Comechingones. Diario La Voz del Interior. Recuperado de: http://archivo.lavoz.com.ar/nota.asp?nota_ id $=127814$

" Cañuqueo, L. (2015). El territorio relevado, el territorio disputado. Apuntes sobre la implementación de Ley nacional 26.160 en Río Negro, Argentina. Revista de Geografía Norte Grande, 62, 11-28.

" Cañuqueo, L, Kropff, L. y Pérez, P. (2015). A la sombra del estado: Comunalización indígena en parajes de la pre cordillera de Río Negro, Argentina. Revista del Museo de Antropología, 8(2), 59-170.

" Cardoso de Oliveira, R. (2007 [1992]). Etnicidad y estructura social. México: Centro de Investigaciones y Estudios Superiores en Antropología Social, Universidad Autónoma Metropolitana.

" Castro Olañeta, I. y Tell, S. (2016). Los pueblos de indios de Córdoba del Tucumán y el pacto colonial. Siglos XVII a XIX. Revista del Museo de Antropología, 9(2), 209-220.

» Cladera, G. (2013). La trashumancia ganadera como acto político: movilidad estacional pastoril y negociación de identidades indígenas ante el Estado en las sierras del Zenta (pcias. Jujuy y Salta). Anales de la X Reunión de Antropología del Mercosur. Córdoba, Universidad Nacional de Córdoba.

》 Clifford, J. (2010). Diversidad de experiencias indígenas: diásporas, tierras natales y soberanías. En M. de la Cadena y O. Starn (Eds.), Indigeneidades contemporáneas: cultura, política y globalización (pp. 221-249). Lima: Editorial IEP.

" Cowan Ross, C. y Nussbaumer, B. (2013). "Comunidad indígena": (des)encuentros de sentidos entre miembros de la institucionalidad pública y de comunidades aborígenes del departamento de Yavi, provincia de Jujuy. Cuadernos de Antropología Social, 37, 109-137.

» De la Cadena, M. y Starn, O. (2010). Introducción. En M. de la Cadena y O. Starn (Eds.), Indigeneidades contemporáneas: cultura, política y globalización (pp. 9-42). Lima: Editorial IEP.

》 Del Río, W. y Pérez, P. (2011). Territorializaciones y prácticas estatales: percepciones del espacio social luego de la Conquista del Desierto. En P. Navarro Floria y W. Del Río (Eds.), Cultura y Espacio: Araucanía- Norpatagonia (pp. 237254). Bariloche: UNRN-IIDyPCa.

»Deleuze, G. y Guattari, F. (1994). Mil mesetas: capitalismo y esquizofrenia. Valencia: Ed. Pre-textos.

》Escobar, A. (2014). Sentipensar con la tierra. Nuevas lecturas sobre desarrollo, territorio y diferencia. Medellín: Ediciones UNAULA.

"Escolar, D. (2007). Los dones étnicos de la Nación. Identidades huarpe y modos de producción de soberanía en Argentina. Buenos Aires. Prometeo.

» Franzi Moreno, T. (2011). Yo soy ticas del Pueblo Nación Comechingón. Noka kani Ticas. Villa Carlos Paz: Ed. Eduvim. 
» Gordillo, G. (2010). Deseando otro lugar: reterritorializaciones guaraníes. En G. Gordillo y S. Hirsch (Eds.), Movilizaciones indígenas e identidades en disputa en la Argentina (pp. 207-236). Buenos Aires: La Crujía.

» Gupta, A. y Ferguson, J. (2008). Más allá de la "cultura": espacio, identidad y las políticas de la diferencia. Antípoda, 7, 233-256.

» Haesbaert, R. (2004). O mito da Desterritorializaçao. Do "fim dos territórios" à multiterritorialidade. Rio de Janeiro: Ed. Bertrand.

» Hall, S. (2003 [1996]). Introduction: Who needs 'Identity'? En S. Hall y P. Du Guy (Eds.), Questions of Identity (pp. 1-17). Londres: Sage Publications.

» Handler, R. (1986). Authenticity. Anthropology Today, 2(1), 2-4.

» Harley, B. (2005). La nueva naturaleza de los mapas. Ensayos sobre la historia de la cartografía. México: Fondo de Cultura Económica.

» Harvey, D. (1994). The Social Construction of Space and Time. A relational theory. Geographical Review of Japan, 67(2), 126-135. [Traducción interna de la cátedra de Epistemología de la Geografía, 2006].

» Hobsbawm, E. y Ranger, T. (2002). La invención de la tradición. Barcelona: Editorial Crítica.

» Katzer, L. (2011). Praxis indígenas y gubernametalidad. Una etnografía de los procesos de producción territorial huarpe en la provincia de Mendoza. Tesis de Doctorado en Ciencias Naturales, Facultad de Ciencias y Museo, Universidad Nacional de La Plata.

» Lazzari, A. (2010). Autenticidad, sospecha y autonomía: la recuperación de la lengua y el reconocimiento del pueblo rankülche en La Pampa. En G. Gordillo y S. Hirsch (Eds.), Movilizaciones indígenas e indentidades en disputa en la Argentina (pp. 147-172). Buenos Aires: La Crujía.

» Malkki, L. (1997). National Geographic: The Rooting of Peoples and Territorialization of National Identity among Scholars and Refuges. En A. Gupta y J. Ferguson, Culture, Power, Place: Explorations in Critical Anthropology (pp. 5274). Durham. Duke University Press.

» Mançano Fernándes, B. (2009). Territorio, teoría y política. En G. Calderon y L. Efraín (Eds.), Descubriendo la espacialidad social en América Latina (pp. 35-66. México: Editorial Itaca.

» Martínez, J. (2010). "Somos resto de gentiles": El manejo del tiempo y la construcción de diferencias entre comunidades andinas. Estudios Atacameños, $39,57-70$.

» Martínez Berrios, N. (2015). Prácticas cotidianas de ancestralización de un territorio indígena: el caso de la comunidad pewenche de Quinquén. Revista de Geografía Norte Grande, 62, 85-107.

» Martínez Berrios, N., Sepúlveda, B. y Palomino Schalscha, M. (2015). La cuestión territorial indígena en América Latina: algunas perspectivas desde Chile y Argentina. Revista de Geografía Norte Grande, 62, 5-9.

» Massey, D. (2008). Pelo espaco. Río de Janeiro: Bertrand.

" Merlan, F. (2010). La indigeneidad como identidad relacional: la construcción de los derechos sobre la tierra en Australia. En M. De la Cadena y O. Starn (Eds.), Indigeneidades contemporáneas: cultura, política y globalización (pp. 141-168). 
Lima, Editorial IEP.

"Nates Cruz, B. (2011). Soportes teóricos y etnográficos sobre conceptos de territorio. Co-herencia, 8(14), 209-229.

»Pacheco de Oliveira, J. (2010). ¿Una etnología de los indios misturados? Identidades étnicas y territorialización en el Nordeste de Brasil. Desacato, 33, 13-32.

"Palladino, L. (2020). Movilizando sentidos de pertenencia comechingones. Una etnografía de los procesos de comunalización y territorialización de las comunidades de La Toma y Ticas. (Provincia de Córdoba). Tesis inédita del doctorado en ciencias antropológicas, Facultad de Filosofía y Humanidades, Universidad Nacional de Córdoba.

» Palladino, L. (2017). Cuidar el monte, devenir indígena. Re-territorialización y comunalización Ticas a partir del conflicto territorial (2015-2017). Cardinalis, 8, 6-31.

»Palladino, L. (2010). Procesos de Comunalización y Territorio. El Caso de la Comunidad Comechingona del Pueblo de La Toma (2008-2009). Tesis inédita de la Licenciatura en Geografía. Departamento de Geografía, Facultad de Filosofía y Humanidades, Universidad Nacional de Córdoba.

»Palomino Schalscha, M. (2015). Descolonizar la economía: espacios de economías diversas y ontologías mapuche en Alto Biobío, Chile. Revista de Geografía Norte Grande, 62, 67-83.

»Porto Gonçalves, C. (2004). A geograficidade do social: uma contribuição para o debate metodológico sobre estudos de conflito e movimentos sociais na América Latina. En J. Seoane (Comp.), Movimientos Sociales y Conflicto en América Latina (pp. 279-285). Buenos Aires: CLACSO.

»Pratt, M. (2010). Epílogo: la indigeneidad hoy. En De la Cadena y O. Starn (Eds.), Indigeneidades contemporáneas: cultura, política y globalización (pp. 437-444). Lima: Editorial IEP.

》Ramos, A.M. (2016). Un mundo en restauración: relaciones entre ontología y política entre los mapuche. Avá, 29, 131-154.

»Ramos, A. (2005). Narrativas de origen y sentidos de pertenencia. Runa, 25, 123142.

》 Ramos, A. y Del Rio, W. (2011). Mapas y narrativas de desplazamiento. Memorias mapuche-tehuelche sobre el sometimiento estatal en Norpatagonia. Antíteses, 4(8), 483-499.

»Salamanca, C. (2012). Alecrin, cartografías para territorios en emergencia. Rosario: UNR Editora.

» Saldi, L. (2012). Procesos de comunalización y territorialización indígena: disputas, rupturas y alianzas en el caso huarpe (centro-oeste argentino). Cuadernos Interculturales, 10(19), 137-171.

"Segato, R. (2007). La Nación y sus Otros: Raza, etnicidad y diversidad religiosa en tiempos de Políticas de la Identidad. Buenos Aires: Prometeo.

»Serrano, A. (1945). Los Comechingones. Córdoba: Imprenta de la Universidad Nacional de Córdoba.

"Stagnaro, M. (2014). "Casi desde la nada": Narrativas, organización y subjetividades en la reemergencia de originarios urbanos comechingones en la 
LUCAS PALLADINO

ciudad de Córdoba, Argentina. Tesis de Maestría inédita. Córdoba. Facultad de Filosofía y Humanidades. Universidad Nacional de Córdoba.

»Szulc, A. (2004) Mapuche se es también en la waria (ciudad). Disputas en torno a lo rural, lo urbano y lo indígena en La Argentina. En: Política y Sociedad. 42 (3). Pp. 167-180.

» Tally, E. (2012). Las interpretaciones New Age y mayas del oxlajuj B'aqtun-2012. CAS. Tercer Coloquio de Antropología y sociología, 41-58.

» Turner, V. (1988). El proceso ritual. Estructura y antiestructura. Madrid: Taurus.

»Ulloa, A. (2005). Las representaciones sobre los indígenas en los discursos ambientales y de desarrollo sostenible. En D. Mato (Coord.), Políticas de economía, ambiente y sociedad en tiempos de globalización (pp. 89-109). Caracas: Facultad de Ciencias Económicas y Sociales, Universidad Central de Venezuela.

»Quirós, J (2014). Neoaluvión zoológico. Avatares políticos de una migración de clase. Cuadernos de antropología social, 39, 9-38.

»Virilio, P. (1997). Fin de l'historie, ou fin de la géographie. Un monde surexposé. Le monde diplomatique, 17. Recuperado de: https://www.monde-diplomatique. $\mathrm{fr} / 1997 / 08 /$ VIRILIO/4878.

Lucas Palladino / zpalladino@hotmail.com

Lic. en Geografía. Doctor en Antropología. Profesor titular en Introducción al Pensamiento Geográfico de la carrera de Geografía de la Universidad Nacional de Córdoba. 